\title{
Article \\ Cyclodextrins Allow the Combination of Incompatible Vancomycin and Ceftazidime into an Ophthalmic Formulation for the Treatment of Bacterial Keratitis
}

\author{
Yassine Bouattour ${ }^{1}$ (D), Florent Neflot-Bissuel ${ }^{2}$, Mounir Traïkia ${ }^{3}$, Anne-Sophie Biesse-Martin ${ }^{3}$, Robin Frederic ${ }^{4}$, \\ Mouloud Yessaad $^{2} \mathbb{D}$, Mireille Jouannet ${ }^{2}$, Mathieu Wasiak ${ }^{2}$, Philip Chennell ${ }^{1, * \mathbb{D}}$ and Valerie Sautou ${ }^{1}$ (D)
}

1 Université Clermont Auvergne, CHU Clermont Ferrand, Clermont Auvergne INP, CNRS, ICCF, F-63000 Clermont-Ferrand, France; ybouattour@chu-clermontferrand.fr (Y.B.); vsautou@chu-clermontferrand.fr (V.S.)

2 CHU Clermont-Ferrand, Pôle Pharmacie, F-63000 Clermont-Ferrand, France; bissuelflorent@orange.fr (F.N.-B.); myessaad@chu-clermontferrand.fr (M.Y.); mjouannet@chu-clermontferrand.fr (M.J.); mwasiak@chu-clermontferrand.fr (M.W.)

3 Université Clermont Auvergne, CNRS, SIGMA-Clermont, ICCF, F-63000 Clermont-Ferrand, France; mounir.traikia@uca.fr (M.T.); a-sophie.biesse-martin@uca.fr (A.-S.B.-M.)

4 Université Clermont Auvergne, Inserm U1071, INRA USC2018, F-63000 Clermont-Ferrand, France; frobin@chu-clermontferrand.fr

Citation: Bouattour, Y.;

Neflot-Bissuel, F.; Traïkia, M.;

Biesse-Martin, A.-S.; Frederic, R.;

Yessaad, M.; Jouannet, M.; Wasiak, M.; Chennell, P.; Sautou, V. Cyclodextrins

Allow the Combination of

Incompatible Vancomycin and

Ceftazidime into an Ophthalmic

Formulation for the Treatment of Bacterial Keratitis. Int. J. Mol. Sci. 2021, 22, 10538. https://doi.org/ 10.3390/ijms221910538

Academic Editors: Zyryanov Grigoriy and Sougata Santra

Received: 29 July 2021

Accepted: 27 September 2021

Published: 29 September 2021

Publisher's Note: MDPI stays neutral with regard to jurisdictional claims in published maps and institutional affiliations.

Abstract: Ceftazidime (CZ) and vancomycin (VA) are two antibiotics used to treat bacterial keratitis. Due to their physical incompatibility (formation of a precipitate), it is not currently possible to associate both molecules in a single container for ophthalmic administration. We firstly characterized the incompatibility then investigated if 2-hydroxypropyl-beta $(\mathrm{HP} \beta \mathrm{CD})$ and 2-hydroxypropyl-gamma cyclodextrins ( $\mathrm{HP} \gamma \mathrm{CD}$ ) could prevent this incompatibility. The impact of $\mathrm{pH}$ on the precipitation phenomena was investigated by analysing the supernatant solution of the mixture using high performance liquid chromatography. A characterization of the inclusion of $\mathrm{CZ}$ with $\mathrm{HP} \gamma \mathrm{CD}$ using ${ }^{1} \mathrm{H}$ nuclear magnetic resonance (NMR), and VA with $\mathrm{HP} \beta \mathrm{CD}$ using ${ }^{1} \mathrm{H}-\mathrm{NMR}$ and a solubility diagram was performed. A design of experiment was built to determine the optimal conditions to obtain a formulation that had the lowest turbidity and particle count. Our results showed that VA and CZ form an equimolar precipitate below $\mathrm{pH}$ 7.3. The best formulation obtained underwent an in-vitro evaluation of its antibacterial activity. The impact of HPCDs on incompatibility has been demonstrated through the inclusion of antibiotics and especially VA. The formulation has been shown to be able to inhibit the incompatibility for $\mathrm{pH}$ higher than 7.3 and to possess unaltered antibacterial activity.

Keywords: cyclodextrins; vancomycin; ceftazidime; ophthalmic solution; bacterial keratitis; nuclear magnetic resonance; design of experiments

\section{Introduction}

Infectious keratitis is a severe sight-threatening ocular infection with increasing prevalence worldwide, ranging from 2.5 to 799 cases per 100,000 population/year [1], despite it also probably being under reported. It is one of the most important causes of corneal opacifications, which is the second most common cause of blindness after cataracts, reportedly causing up to $5 \%$ of all blindness cases [2]. Of these infections, bacterial keratitis (BK) represents the most common (>90\%) type of infectious keratitis in most regions of the world [1]. This infection is mainly caused by extended-contact lens wear and ocular trauma, even if other causes have been documented [3,4]. Symptoms include sudden pain in the eye, unusual eye redness, reduced vision, increased light sensitivity, excessive tearing and eye discharge, and in the end if without treatment, blindness. The most commonly isolated 
pathogens responsible for BK are still Pseudomonas aeruginosa, Staphylococcus areus, but other organisms are on the rise such as coagulase-negative Staphylococci, as well as Streptococci spp. and Moraxella spp. $[1,2,5,6]$. Unfortunately, identifying the causal pathogen to be able treat it with the appropriate antibiotic takes laboratory time that the patient often does not have, which is why an empiric treatment of antibiotic eye drops covering the spectra of the most common bacteria is recommended [7-9]. Those eye drops are given to the hospitalized patient every 5 to $10 \mathrm{~min}$ the first hour, then every hour (day and night) for $48 \mathrm{~h}$ before being reduced to hourly (daytime only) for several days. Amongst the active pharmaceutical ingredients (API) that can be used are vancomycin (VA) and ceftazidime (CZ), used at concentrations ranging usually from 25 to $50 \mathrm{mg} \mathrm{mL}^{-1}$. VA is a much-used glycopeptide that acts by blocking peptidoglycan synthesis of the bacterial wall, leading to leakage of intracellular components, which gives it bactericidal properties [10]. However, due to its high molecular weight, it cannot penetrate the pores of the outer membrane of Gram-negative bacteria. Its spectrum of action is therefore limited to Gram-positive bacteria such as Staphylococcus aureus or Streptococcus spp. CZ is a third-generation cephalosporin (group of beta-lactam antimicrobials) that possess a beta-lactam ring that binds to the penicillin-binding protein and inhibit its normal activity. Unable to synthesize a cell wall, the bacteria die [11]. CZ is active against Gram-positive and Gram-negative bacteria, including those resistant to other antibiotics. Very importantly, $\mathrm{CZ}$ also is also effective against Pseudomonas aeruginosa. The chemical structures of these API are presented Figure 1. Both these drugs are only marketed for intravenous administration, meaning that compounding pharmacies must prepare the eye drops needed for treatment. Unfortunately, these two API cannot be given simultaneously as they are incompatible when mixed together, forming a cloudy white precipitate [12] that cannot be safely administered to the patient. This incompatibility also manifests itself between VA and other cephalosporins [12] as well as when the drugs are administered sequentially yet separately [13], meaning that in practice the nurse administering each eye drop of the different antibiotic must wait several minutes between the two antibiotics, which is a time consuming and inefficient task.
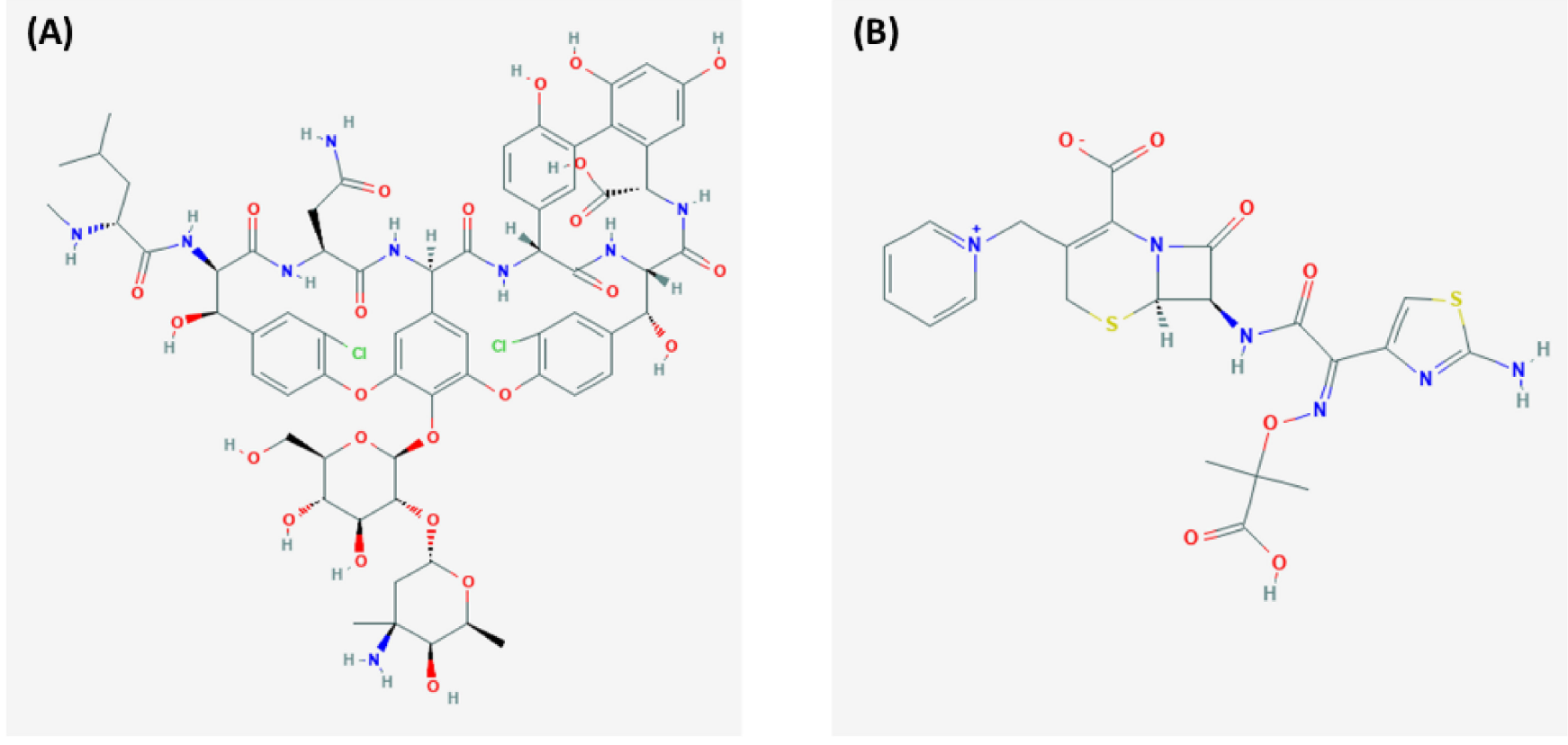

Figure 1. Chemical structure of vancomycin (A) and ceftazidime (B). Publicly available from [14].

Cyclodextrins (CDs) are cyclic natural oligosaccharides consisting of $6(\alpha \mathrm{CD}), 7(\beta C D)$ or $8(\gamma \mathrm{CD})$ glucose monomers linked via $\alpha-1,4$-glycosidic bonds. The molecules are shaped similar to a doughnut with a hydrophilic outer surface and a somewhat lipophilic central cavity. The natural CDs and their complexes being rather poorly water-soluble, derivatives 
such as for example 2-hydroxypropyl- $\beta C D(\mathrm{HP} \beta C D)$ and 2-hydroxypropyl- $\gamma \mathrm{CD}(\mathrm{HP} \gamma \mathrm{CD})$ with solubilities higher than $500 \mathrm{mg} / \mathrm{mL}$ have been chemically prepared. Many uses have been described for the compounds, including as a useful excipient for drug preparation and delivery, as they can temporarily camouflage undesirable API physiochemical properties such as low aqueous solubility or poor stability through formation of drug/CD inclusion complexes, for example for parenteral medications [15]. Their use as also been described for drug delivery of ocular therapeutics, for surface, anterior and posterior segments of the eye [16-19] and are considered more and more as safe and effective for this use. Interestingly, their use as potential drug carriers that could block the precipitation interaction between VA and CZ has to our knowledge not been published. As VA has been shown to complex itself with $\beta C D[20,21]$, and $C Z$ with $\gamma C D$ [22], the rationale of this study was to use both $\beta$ and $\gamma C D$ (in their 2-hydroxypropyl derivative) to investigate their potential for blocking the problematic incompatibility between VA and CZ, and thus pave the way for the development of a novel ophthalmic solution combining these two useful antibiotics.

\section{Results}

\subsection{Preliminary Investigation of Ceftazidime-Vancomycin Incompatibility}

For $25 \mathrm{mg} \mathrm{mL}^{-1} \mathrm{CZ}$ solutions, a variation of the $\mathrm{pH}$ between 4 and 9 did not cause any visible precipitation. However, for $25 \mathrm{mg} \mathrm{mL}^{-1}$ VA solutions, a highly visible precipitation was noticed for $\mathrm{pH}$ values between 7.3 and 8.4. When combined, the CZ/VA mixture (target concentration of $25 \mathrm{mg} \mathrm{mL}^{-1}$ ) was completely incompatible (visible white precipitation) for $\mathrm{pH}$ ranging from 3 to 8.4 , but we noticed that the precipitation was less intense when the $\mathrm{pH}$ was between 7.3 and 8.4. The mixture showed no signs of visible precipitation at a pH above 8.4 (See Supplementary Materials File S1).

A quantification of both antibiotics in the supernatant liquid after centrifugation, performed for a final $\mathrm{pH}$ of the mixture at $\mathrm{pH}=7$ and $\mathrm{pH}=8$, showed reduced concentrations of both VA and CZ, but especially for VA for which concentrations were reduced by 27.7 and $50.0 \%$ at $\mathrm{pH}=7$ and $\mathrm{pH}=8$, respectively (see Table 1 ). When the concentrations are expressed in $\mathrm{mmol} \mathrm{L}^{-1}$, it can be seen that at $\mathrm{pH} 7 \mathrm{VA}$ and $\mathrm{CZ}$ lost an equal amount of matter (12.05 and $\left.11.51 \mathrm{mmol} \mathrm{L}^{-1}\right)$ whereas at $\mathrm{pH} 8$ the loss of VA was 4 times greater than $\mathrm{CZ}$ (8.33 versus $2.31 \mathrm{mmol} \mathrm{L}^{-1}$ ). The analysis of some recovered precipitate showed the presence of both VA and CZ. The amount of each compound in the tested precipitate was found to be of $0.03 \mu \mathrm{moL}$.

Table 1. Ceftazidime (CZ) and vancomycin (VA) concentrations in the supernatant after centrifugation of the solution mixture, as a function of the mixture $\mathrm{pH}$. RSD: relative standard deviation.

\begin{tabular}{|c|c|c|c|c|c|c|c|}
\hline & \multirow{2}{*}{$\begin{array}{c}\text { Initial } \\
\text { Concentration } \\
\left(\mathrm{mg} \mathrm{mL}^{-1}\right)\end{array}$} & \multirow{2}{*}{$\begin{array}{l}\mathrm{pH} \text { of the } \\
\text { VA/CZ } \\
\text { Mixture }\end{array}$} & \multicolumn{2}{|c|}{$\begin{array}{l}\text { Concentration }\left(\mathrm{mg} \mathrm{mL}^{-1}\right) \text { in the } \\
\text { Supernatant }(n=3)\end{array}$} & \multirow{2}{*}{$\begin{array}{l}\% \text { of Initial } \\
\text { Concentration }\end{array}$} & \multirow{2}{*}{$\begin{array}{c}\text { Initial } \\
\text { Concentration } \\
\left(\mathrm{mmol} \mathrm{L}^{-1}\right)\end{array}$} & \multirow{2}{*}{$\begin{array}{c}\text { Loss } \\
\left(\mathrm{mmol} \mathrm{L}^{-1}\right)\end{array}$} \\
\hline & & & Average & RSD & & & \\
\hline \multirow{2}{*}{ Vancomycin } & \multirow{2}{*}{24.16} & 7 & 6.69 & $6.26 \%$ & $27.7 \%$ & \multirow{2}{*}{16.67} & 12.05 \\
\hline & & 8 & 12.08 & $6.92 \%$ & $50.0 \%$ & & 8.33 \\
\hline \multirow{2}{*}{ Ceftazidime } & \multirow{2}{*}{21.95} & 7 & 15.66 & $6.14 \%$ & $71.4 \%$ & \multirow{2}{*}{40.16} & 11.51 \\
\hline & & 8 & 20.69 & $6.62 \%$ & $94.3 \%$ & & 2.31 \\
\hline
\end{tabular}

\subsection{Antibiotics Inclusion Characterization in Hpcds}

\subsubsection{Nuclear Magnetic Resonance (NMR) Analyses}

\section{${ }^{1} \mathrm{H}$ NMR-Spectroscopy Chemical Shifts Measurements}

By superimposing the spectra of a $50 \mathrm{mg} / \mathrm{mL} \mathrm{CZ}$ and the $\mathrm{CZ} / \mathrm{HP} \gamma \mathrm{CD}$ (1:3 ratio) solution at $\mathrm{pH} 4$, variations between the two spectra, as a shift in the peaks of $\mathrm{CZ}$ towards the lowest frequencies (high field) was clearly present. This was observed even more so on the enlargement between 5.5 and $6 \mathrm{ppm}$. The RMN analysis revealed a decrease in the resolution and widening of the peaks. Those shifts were also found at $\mathrm{pH} 8$ for $\mathrm{CZ}$ confirming its inclusion in $\mathrm{HP} \gamma \mathrm{CD}$. Similar results were also found when comparing VA 
and the VA/HP $\beta C D$ (1:5 ratio) solutions at $50 \mathrm{mg} \mathrm{mL}^{-1}$ and at $\mathrm{pH} 3$ (Figure 2). Full chemical shift details and peak attribution are supplied in Supplementary Materials S1 for $\mathrm{CZ}$ and CZ/HP $\gamma \mathrm{CD}$. As VA is a larger and more complex molecule $\left(1449.2 \mathrm{~g} / \mathrm{mol}^{-1}\right)$, signal analysis is much more difficult, especially as the peaks also broaden after the inclusion, and chemical shift analysis was not performed. In addition, the average molecular weight of the cyclodextrins were estimated by NMR and were found to be of $1527-1568 \mathrm{~g} / \mathrm{mol}^{-1}$ (HPßCD) and 1690-1705 g/ $\mathrm{mol}^{-1}(\mathrm{HP} \gamma \mathrm{CD})$.

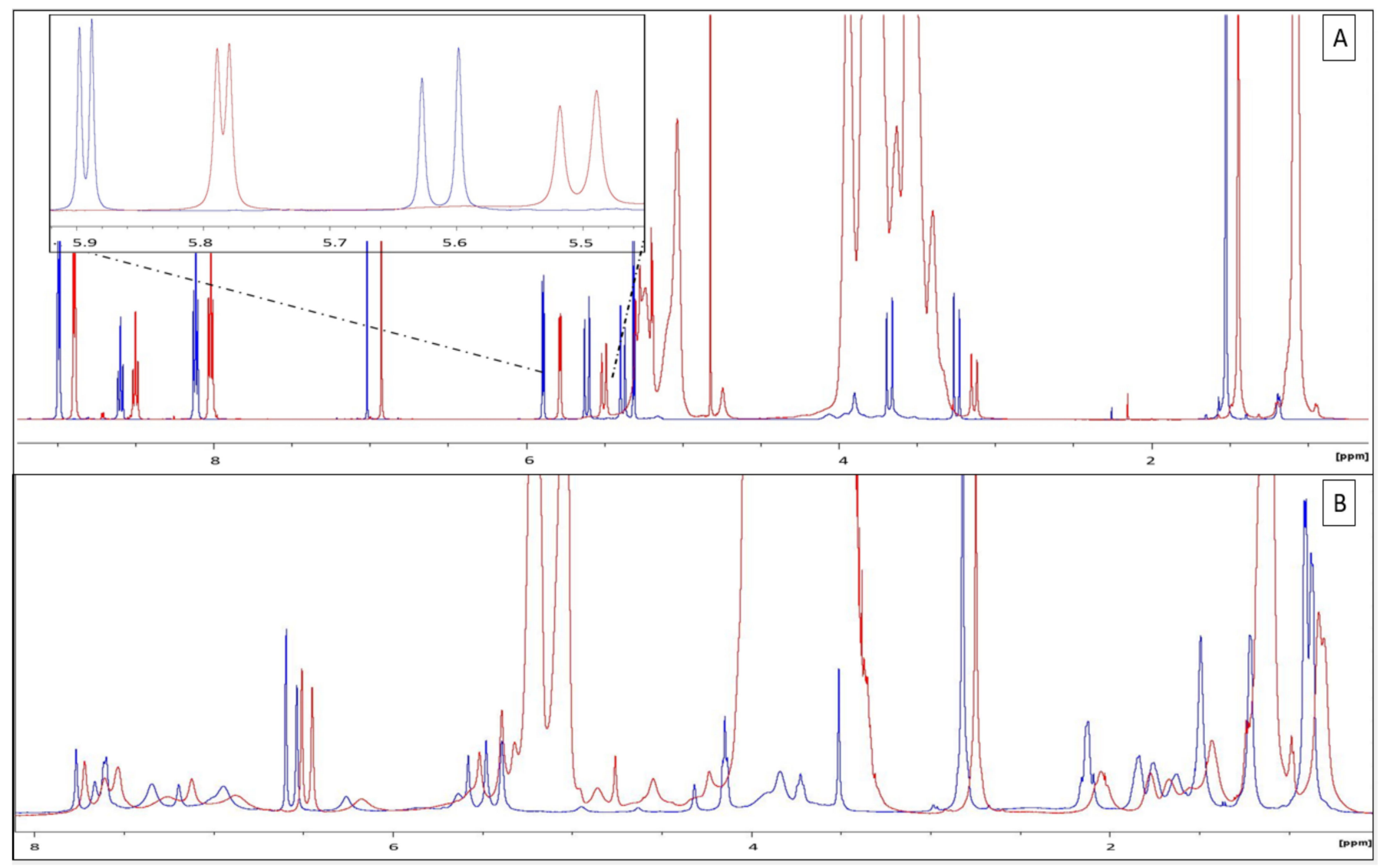

Figure 2. Nuclear magnetic resonance spectra of (A) ceftazidime (blue curve) and ceftazidime/hydroxypropyl- $\gamma$ cyclodextrins (red curve) at $50 \mathrm{mg} / \mathrm{mL}$ at $\mathrm{pH} \mathrm{4,} \mathrm{(B)} \mathrm{vancomycin} \mathrm{(blue} \mathrm{curve)} \mathrm{and} \mathrm{vancomycin/hydroxypropyl-} \beta$ cyclodextrins (red curve) at $50 \mathrm{mg} / \mathrm{mL}$ at $\mathrm{pH} 4$.

\section{${ }^{1} \mathrm{H}$ NMR-Diffusion Measurements ( ${ }^{1} \mathrm{H}$-DOSY)}

The DOSY superimposition of the spectra of $\mathrm{CZ}, \mathrm{HP} \gamma \mathrm{CD}$ and the $\mathrm{CZ} / \mathrm{HP} \gamma \mathrm{CD}$ mixture showed an increase in the apparent size of $\mathrm{CZ}$ and $\mathrm{HP} \gamma \mathrm{CD}$ in the mixture compared to their initial size when analysed alone. The same results were found when analysing VA, $\mathrm{HP} \beta C D$ and the VA/HP $\beta C D$ mixture solution. The apparent size of both antibiotics in their respective cyclodextrins solution was greater than the apparent size of CDs in the mixture (Figure 3). 


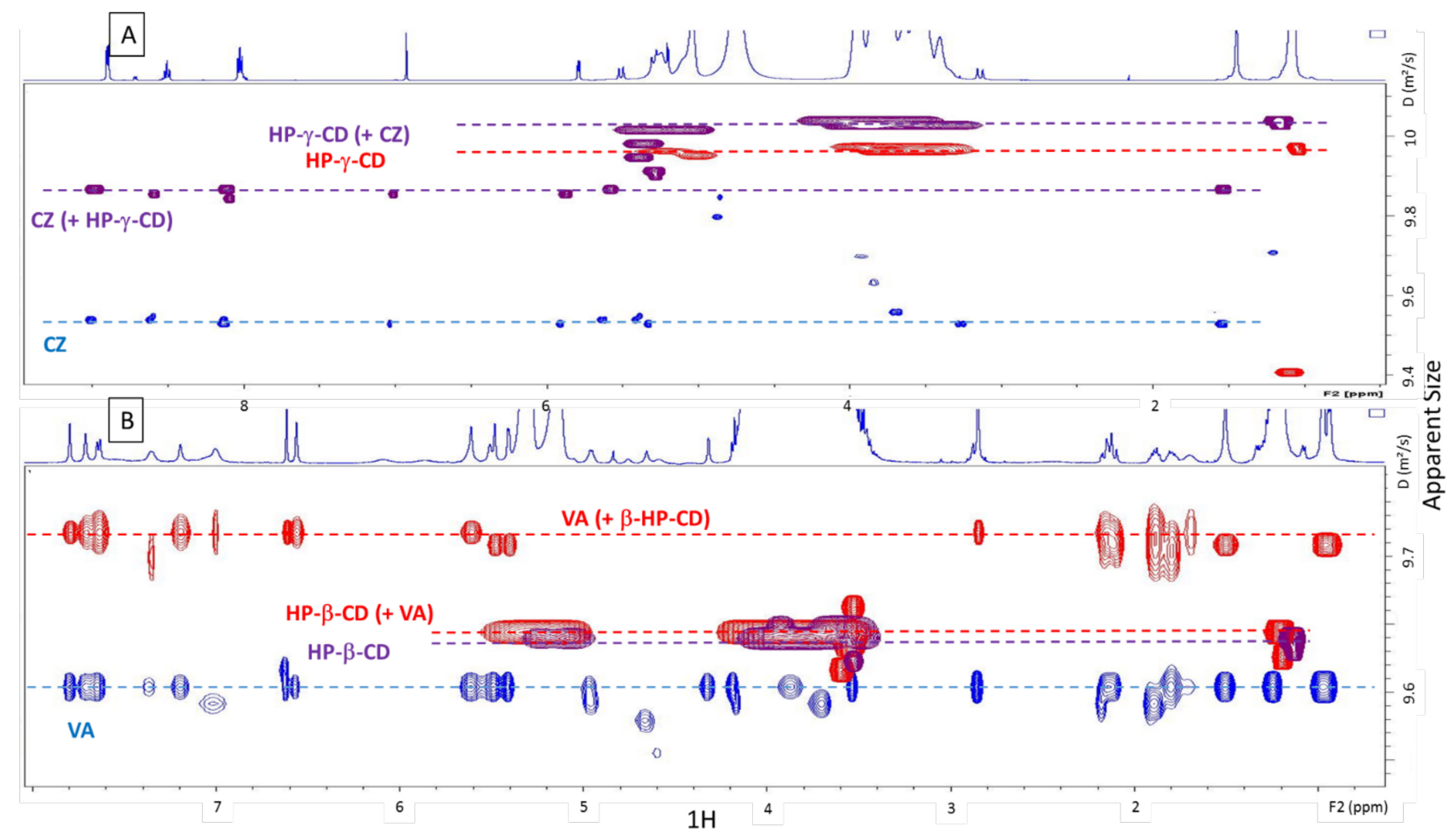

Figure 3. The ${ }^{1} \mathrm{H}$-diffusion ordered spectroscopy spectra of (A) ceftazidime (CZ, blue curve), hydroxypropyl- $\gamma$-cyclodextrins (HP $\gamma \mathrm{CD}$, red curve) alone and in mixture at $50 \mathrm{mg} \mathrm{ml}^{-1}$ and at $\mathrm{pH} 4$ (purple curve) and (B) of vancomycin (VA, blue curve), hydroxypropyl- $\beta$-cyclodextrins (HP $\beta C D$, purple curve) alone and in mixture at $50 \mathrm{mg} / \mathrm{mL}$ and at $\mathrm{pH} 3$ (red curve).

\subsubsection{Influence of $\mathrm{HP} \beta \mathrm{CD} /$ Vancomycin Molar Ratio on Vancomycin Inclusion} and Precipitation

In order to investigate the impact of $\mathrm{HP} \beta \mathrm{CD}$ concentrations on VA solubility at $\mathrm{pH}$ 8 (at a concentration of $50 \mathrm{mg} / \mathrm{mL}$ ), various molar ratios of HP $\beta C D / V A$ were tested for visible signs of precipitation after up to $48 \mathrm{~h}$ of storage at $22{ }^{\circ} \mathrm{C}$. The results presented in (Figure 4A) showed that after $15 \mathrm{~min}$, a molar ratio of 7:1 can solubilize the molecule ( $97.0 \%$ of theoretical concentration) and avoid visible signs of precipitation. However, this ratio did not prevent the solution from precipitating after $24 \mathrm{~h}$ hours of storage. Indeed, a molar ratio of 10:1 was found to be necessary to maintain solution limpidity even after $48 \mathrm{~h}$ of storage, which was confirmed by the vancomycin quantification results $(97.3 \%$ of theoretical concentration in the supernatant), thus indicating complete vancomycin solubility, see (Figure 4B).

\subsection{Determination of the Optimum Preparation Method Using Design of Experiments}

The mean impact of the parameters tested during the 84 experiments on visual aspect, turbidity, particulate count and osmolality was calculated when these parameters varied from the minimum to the maximum value, as represented in Table 2. Full experimental data are supplied in the Supplementary Materials File S1. The two factors that had the most positive impact (decreasing physical incompatibility signs) were the $\mathrm{pH}$ of the final mixture and the concentration of the cyclodextrins, and the factor which had the most negative impact (increasing incompatibility signs) was the $\mathrm{pH}$ of the $\mathrm{CD}$-antibiotic complexation. The stirring time had no interpretable effect. 

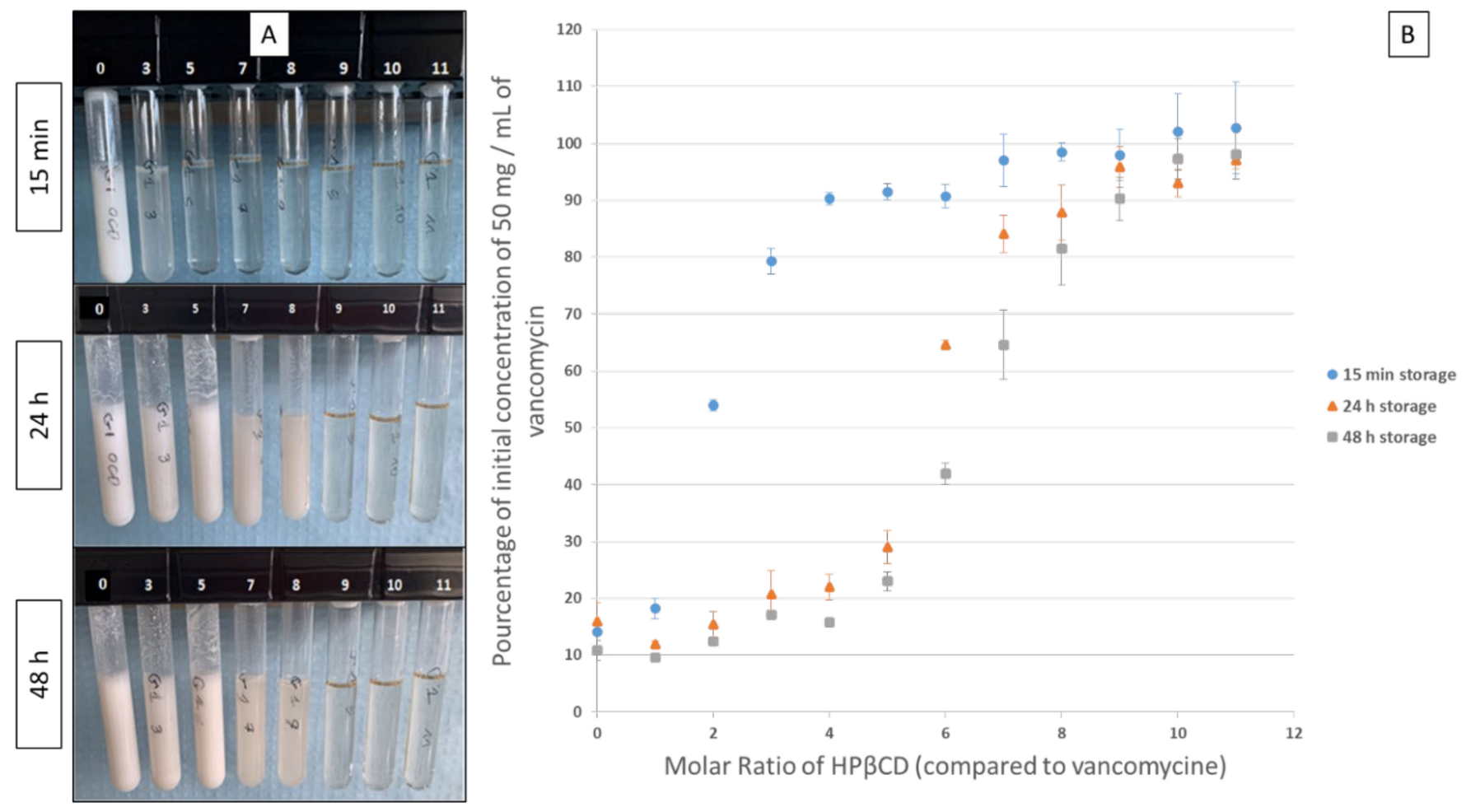

Figure 4. Influence of hydroxypropyl- $\beta$-cyclodextrins $(\mathrm{HP} \beta C \mathrm{CD}) /$ vancomycin molar ratio on vancomycin inclusion and precipitation at $\mathrm{pH} 8$ as function of the $\mathrm{HP} \beta \mathrm{CD} /$ vancomycin molar ratio immediately after preparation and after up to $48 \mathrm{~h}$ hours of storage: (A) visual aspect (the white numbers indicate the $\mathrm{HP} \beta \mathrm{CD}$ /vancomycin molar ratio of the solutions and (B) vancomycin concentration ( $n=3$, mean \pm standard deviation). $\mathrm{h}=$ hour.

In order to visually comprehend the impact of these parameters and determine the optimum preparation method, a four-dimensional representation was elaborated, using turbidity as the main response factor (see Figure 5).

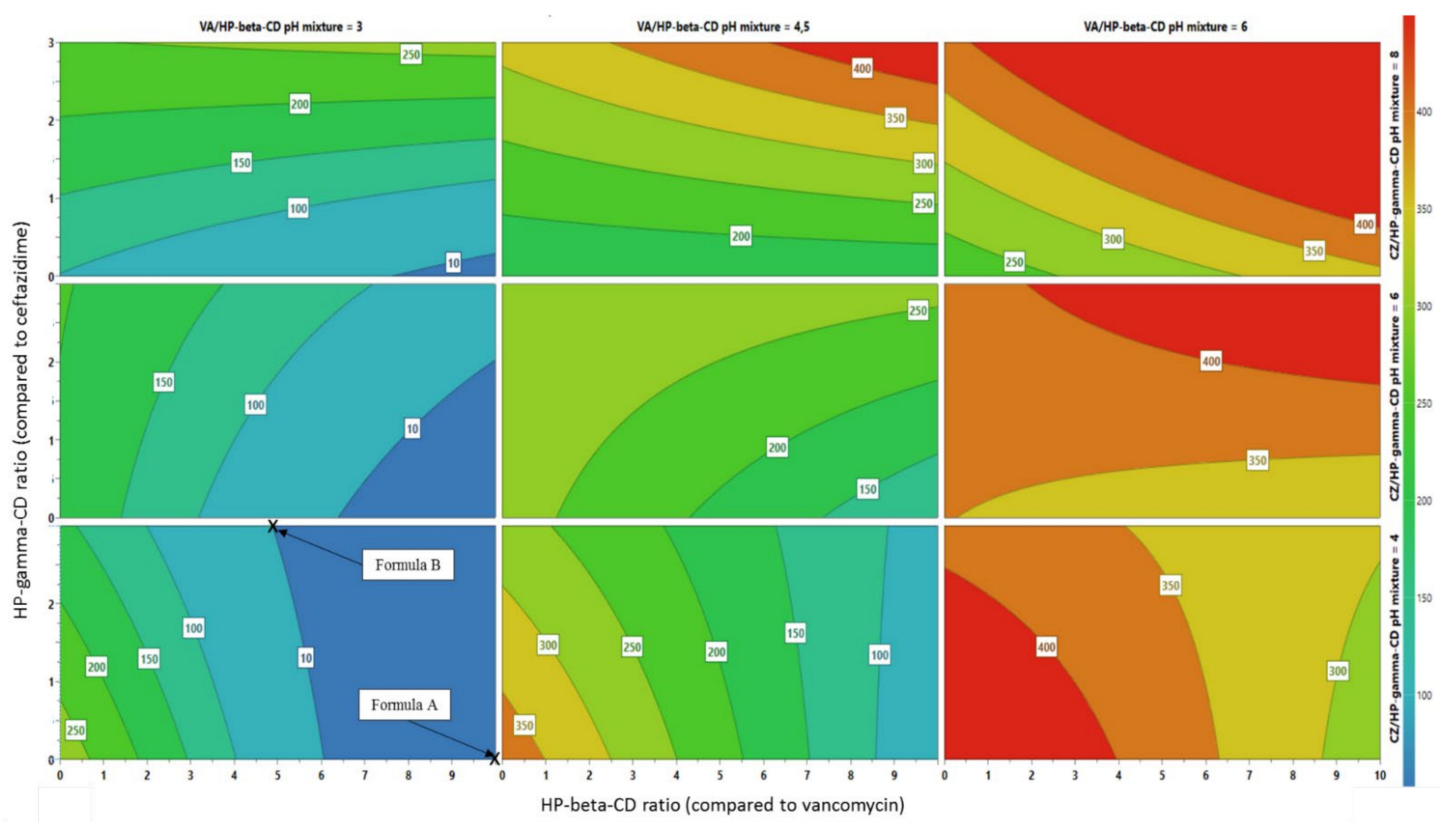

Figure 5. Variation of turbidity as function of simultaneous variation of parameters when stirring time of hydroxypropyl$\beta$-cyclodextrins (HP $\beta C D$ ) - vancomycin (VA) fixed at $2 \mathrm{~h}$, stirring time of Hydroxypropyl- $\gamma$-cyclodextrins (HP $\gamma \mathrm{CD}-$ ceftazidime $(\mathrm{CZ})$ fixed at $0.5 \mathrm{~h}$ and final $\mathrm{pH}$ of the solution is at 8 . 
Table 2. Parameters relative impact on the studied responses according to the design of experiments. Hydroxypropyl- $\beta$ cyclodextrins: $\mathrm{HP} \beta C D$; hydroxypropyl- $\gamma$-cyclodextrins: $\mathrm{HP} \gamma \mathrm{CD}$; VA: vancomycin; $\mathrm{CZ}$ : ceftazidime.

\begin{tabular}{|c|c|c|c|c|c|}
\hline \multirow[b]{2}{*}{ Parameters } & \multicolumn{5}{|c|}{ Average Response (When Parameters Vary from Minimum to Maximum) } \\
\hline & $\begin{array}{c}\text { Visual } \\
\text { Examination }\end{array}$ & Turbidity & $\begin{array}{c}\geq 10 \mu \mathrm{m} \text { Particles } \\
\text { Count }\end{array}$ & $\begin{array}{c}\leq 10 \mu \mathrm{m} \text { Particles } \\
\text { Count }\end{array}$ & Osmolality \\
\hline HP $\beta C D$ Concentration & -0.39 & -50.03 & -140 & 7 & 103 \\
\hline $\mathrm{HP} \gamma \mathrm{CD}$ Concentration & -0.47 & -56.09 & -787 & -235 & 73 \\
\hline $\mathrm{pH}$ mixture of $\mathrm{HP} \beta C D / V A$ & 0.11 & 22.76 & 498 & 417 & -8 \\
\hline $\mathrm{pH}$ mixture of $\mathrm{HP} \gamma \mathrm{CD} / \mathrm{CZ}$ & 0.35 & 33.14 & 109 & 176 & -41 \\
\hline Stirring duration of $\mathrm{HP} \beta \mathrm{CD} / \mathrm{VA}$ & -0.28 & -44.02 & 157 & 345 & 14 \\
\hline Stirring duration of $\mathrm{HP} \gamma \mathrm{CD} / \mathrm{CZ}$ & 0.3 & 49.08 & -219 & 36 & -2 \\
\hline final $\mathrm{pH}$ of the mixture & -2.33 & -389.86 & -581 & -261 & 14 \\
\hline
\end{tabular}

The optimum conditions yielding the lowest turbidity values are visualized in blue, and the highest (worst) in red. We found that the best conditions were when stirring time of $\mathrm{VA} / \mathrm{HP} \beta \mathrm{CD}$ was set at $2 \mathrm{~h}$, stirring time of $\mathrm{CZ} / \mathrm{HP} \gamma \mathrm{CD}$ was at $30 \mathrm{~min}$, initial $\mathrm{pH}$ mixture of $\mathrm{VA} / \mathrm{HP} \beta \mathrm{CD}$ at 3 and initial $\mathrm{pH}$ mixture of $\mathrm{CZ} / \mathrm{HP} \gamma \mathrm{CD}$ at 4 . We fixed the final $\mathrm{pH}$ solution at 8 to be in the ocular-tolerated $\mathrm{pH}$ range, reported to be between 5 and $8.5[23,24]$. As such, two optimal methods were selected:

Formula A: VA $25 \mathrm{mg} \mathrm{mL}^{-1}, \mathrm{CZ} 25 \mathrm{mg} \mathrm{mL}^{-1}, 50 \mathrm{mM}$ phosphate buffer at $\mathrm{pH} 8$, $\mathrm{HP} \beta C D$ at $250 \mathrm{mg} \mathrm{mL}^{-1}$ (corresponding to a ratio of 10:1 compared to vancomycin);

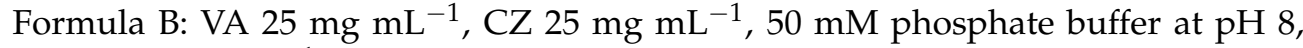
$\mathrm{HP} \beta C \mathrm{CD}$ at $125 \mathrm{mgmL}^{-1}$ (corresponding to a ratio of 5:1 compared to vancomycin) and $\mathrm{HP} \gamma \mathrm{CD}$ at $216.8 \mathrm{mgmL}^{-1}$ (corresponding to a ratio of 3:1 compared to ceftazidime).

\subsection{Validation of the Preparation Method}

The two formulas selected according to the DOE results were prepared in bigger volumes and subjected to $\mathrm{pH}$ variations and refrigerated storage. The variation of $\mathrm{pH}$ from 7.5 to 9 showed no precipitation for the two formulas. However, decreasing $\mathrm{pH}$ below 7.5 resulted in precipitation of the prepared solution for the two formulas. In addition, if placed at $5{ }^{\circ} \mathrm{C}$, we found a precipitate in Formula A but none for Formula B, demonstrating that the latter is the better candidate. After sterilization of Formula B by filtration through a $0.22 \mu \mathrm{m}$ filter, the loss of concentration was found to be negligible $(1.48 \%$ for $\mathrm{CZ}$ and $0.38 \%$ for VA).

\subsection{Verification of the Efficiency Mixture of the Optimized Formula}

In order to investigate the antimicrobial efficacy of the final formulation, disk diffusion tests were performed on three bacterial strains. The results are presented in Table 3 and illustrated in Figure 6. Formula B presented the same results compared to reference solution of CZ and VA solution, and showed a preserved activity against Escherichia coli ATCC 25922), Staphylococcus aureus ATCC 29213 and Pseudomonas aeruginosa ATTC 27853 cultures. 
Table 3. Inhibition diameters of the tested solutions against Escherichia coli, Staphylococcus aureus and Pseudomonas aeruginosa cultures. Mean \pm standard deviation, $n=3$. Hydroxypropyl- $\beta$-cyclodextrins: $\mathrm{HP} \beta \mathrm{CD}$; hydroxypropyl- $\gamma$-cyclodextrins: $\mathrm{HP} \gamma \mathrm{CD}$; VA: vancomycin; $\mathrm{CZ}$ : ceftazidime.

\begin{tabular}{cccc}
\hline & \multicolumn{3}{c}{ Inhibition Diameters (mm) } \\
\cline { 2 - 4 } & $\begin{array}{c}\text { Staphylococcus } \\
\text { aureus }\end{array}$ & $\begin{array}{c}\text { Escherichia } \\
\text { coli }\end{array}$ & $\begin{array}{c}\text { Pseudomonas } \\
\text { aeruginosa }\end{array}$ \\
\hline $\mathrm{HP \gamma CD}$ & $6 \pm 0$ & $6 \pm 0$ & $6 \pm 0$ \\
$\mathrm{HP} \beta \mathrm{CD}$ & $6 \pm 0$ & $6 \pm 0$ & $6 \pm 0$ \\
$\mathrm{CZ}$ & $18 \pm 1$ & $27 \pm 1$ & $26 \pm 1$ \\
$\mathrm{VA}$ & $17 \pm 1$ & $6 \pm 0$ & $6 \pm 0$ \\
$\mathrm{CZ} / \mathrm{HP} \gamma \mathrm{CD}$ & $17 \pm 1$ & $27 \pm 1$ & $25 \pm 1$ \\
$\mathrm{VA} / \mathrm{HP} \beta \mathrm{CD}$ & $16 \pm 1$ & $6 \pm 0$ & $6 \pm 0$ \\
$\mathrm{CZ} / \mathrm{HP}$ CD $+\mathrm{VA} / \mathrm{HP} \beta C D$ & $21 \pm 1$ & $27 \pm 0$ & $26 \pm 0$ \\
mixture (formula B) & & &
\end{tabular}

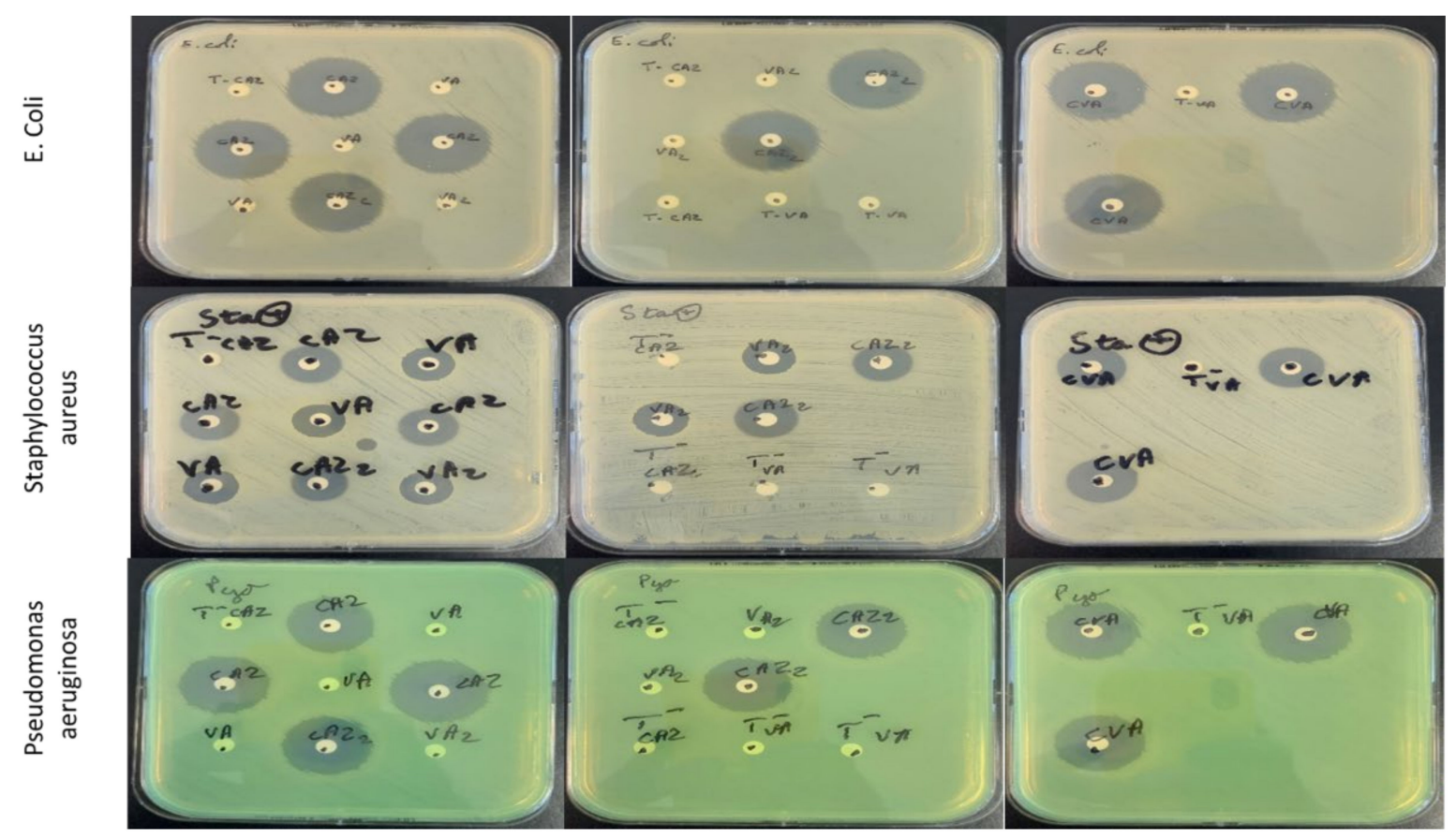

Figure 6. Culture of E. coli ATCC 25922, S. aureus ATCC29213 and P. aeruginosa ATCC27853 after 18 h of incubation at $35^{\circ} \mathrm{C}$ with different antibiotic solutions: T-VA: negative control pH 3 and T-CVZ: pH 4; CZ: Ceftazidime; VA: Vancomycin; CZA2: Ceftazidime $+\mathrm{HP} \beta \mathrm{CD}$ at $\mathrm{pH} 4$; VA2: Vancomycin $+\mathrm{HP} \gamma \mathrm{CD}$ at $\mathrm{pH} 3$; CVA: Formula B.

\section{Discussion}

In this study, we aimed to develop a formulation enabling a physically compatible mix of CZ and VA, each at a concentration of $25 \mathrm{mg} \mathrm{mL}^{-1}$ by using HPCD, in order to obtain an ophthalmic solution that can be used treat BK. This was achieved as we obtained a solution mix of $\mathrm{CZ}$ and VA that was physically devoid of any particulate matter for $\mathrm{pH}$ higher than 7.3 compared to $\mathrm{pH} 8.4$ without HPCD. However, for $\mathrm{pH}$ lower than 7.3, even the use of $\mathrm{HP} \gamma \mathrm{CD}$ and $\mathrm{HP} \beta \mathrm{CD}$ at high concentrations did not prevent the incompatibility.

Incompatibility of CZ and VA has been largely reported since the 90's, especially for intravitreal injection [13,25-27] as well as for parenteral [28] and peritoneal dialysis solutions [29], but its exact mechanism is still not well known. It has been hypothesized that VA precipitation could be due to the presence of sodium carbonate in the CZ formulation used to alkalinize the solution, but was also reported when the solution is carbonate free [12,13]. It was also found to be temperature dependent occurring at $37^{\circ} \mathrm{C}$ but less at ambient temperature, and solvent dependent occurring more with balanced salt solution 
(BSS) than normal saline solution [30]. VA precipitation has also been reported in association with many other drugs such as cephalosporins, gelatine fluid, in BSS or in a pH of 7.5 [31-33]. In this study, we first investigated the incompatibility of the two molecules, using pharmaceutical sources containing no excipients (VA) or only sodium carbonate (CZ). The preliminary observations corroborated the theoretical data namely that: $\mathrm{CZ}$ is soluble at $50 \mathrm{mg} \mathrm{mL}^{-1}$ at whatever $\mathrm{pH}$, the VA however precipitates between $\mathrm{pH} 7.3$ and 8.4, the CZ/VA mixture precipitates from $\mathrm{pH} 4$ to $\mathrm{pH}$ 8.4. After $\mathrm{pH} 8.4$, the solution becomes clear. By analysing computed ionization data for each molecule [34], we noticed that the two antibiotics are of net opposite charges for a $\mathrm{pH}$ between 4 and 7.3 ( -1 for $\mathrm{CZ}$ and +1 for VA). Indeed, as described by Johnson and Yalkowsky [35] the net charge of VA will be at +1 when $\mathrm{pH}$ between 4 and 7 and began to decrease after $\mathrm{pH} 7$ to reach 0 at $\mathrm{pH}$ 8.3. In fact, VA will have two positive chemical moieties (amine functional group) and one negative chemical moiety (acid functional group), which is the total opposite of the ceftazidime at the same range of $\mathrm{pH}$ [34]. They would combine over this $\mathrm{pH}$ range forming a precipitate. Between 7.3 and 8.4, CZ remains negative while the main part of VA becomes molecular, causing a huge drop in its solubility. It would then be this molecular part which would precipitate predominantly over this $\mathrm{pH}$ range, and would therefore shift the HPCD complexation equilibrium as the free species precipitates. After $\mathrm{pH}$ 8.4, the average charge of VA becomes negative similar to that of $\mathrm{CZ}$, which explains why they would no longer associate and therefore no longer precipitate either by incompatibility or by low solubility, as the ionized form is more water soluble. In order to validate the theory, a quantification of each antibiotic in the supernatant of the two mixture (at $\mathrm{pH} 7$ and 8) was carried out using HPLC. The equal amount of matter of VA and CZ lost at $\mathrm{pH} 7\left(12.05\right.$ and $\left.11.51 \mathrm{mmol} \mathrm{L}^{-1}\right)$ is in favour of a 1:1 molar interaction between the two antibiotics, as is the identical amount (in $\mu \mathrm{mol}$ ) of the two antibiotics found in an analysis of a precipitate. This information is also coherent with the findings of Raju et al. [32] who also analysed the precipitate formed when mixing a $10 \mathrm{mg} / \mathrm{mL}$ solution VA with a $20 \mathrm{mg} / \mathrm{mL}$ solution of CZ by HPLC and using microbiological activity assay. They found the presence of both compounds in the precipitate, which also exhibited an antibiotic effect against both S. aureus and E. coli strains. The combination of all these results seemed to confirm that $\mathrm{CZ}$ and VA form an equimolar association which will precipitate before $\mathrm{pH}$ 7.3. Between 7.3 and 8.4, it would be the molecular part of the VA that would be the main source of the precipitation, as well as perhaps a marginal amount of VA/CZ precipitate formed by the interaction of residual positively charged VA with CZ.

The use of $C D$ as carrier molecules for enhancing the solubility of drugs is now a well-known process, and the interaction can be characterized by various solubility diagram studies and analytical methods such as FT-IR, DSC, X-ray and NMR [36-40]. As Misiuk reported [22], it is possible to characterize the inclusion of CZ in a cage molecule using NMR by superimposing the spectrum of the free molecule with the spectrum of the molecule mixed with its cage. Our NMR data showed offsets as well as loss of resolution. This resulted in a broadening of the peaks of the spectrum of antibiotics mixed with their HPCD compared to the spectra of antibiotics alone, which is explained by a change in the environment of the molecule's protons. From a theoretical point of view, this could have been due to different $\mathrm{pHs}$ between solutions, a difference in ionic strength, the viscosity of the medium, or the interaction with another molecule. Here, the pHs were strictly the same and the impact of viscosity was eliminated by diluting the solutions with a suitable buffer which did not change the trend of the results. In order to decide between a difference in ionic strength or an inclusion, a 2D analysis was necessary. It is possible to choose to verify the proximity of the protons of the molecule with those of the cage molecule via a NOESY such as Misiuk [22] or Ja'far et al. [41]. Here, DOSY (2D) [42-44], was preferred as described by Venuti et al. [45] in order to measure the difference in diffusivity between single molecules and the complex. Thus, by superimposing the water signals on the different spectra, the viscosity factor was eliminated. The shift in the signals of the spectra (lower chemical shift for the antibiotic with its HPCD) is the result of the increase 
in the apparent size, and therefore in the average molar mass, thus reflecting an interaction between the HPCDs and their corresponding antibiotics forming a larger complex. It is important to note in the case of the VA that its apparent size and therefore its average molar mass is greater than the apparent size of the HP $\beta C D$ in the mixture. This is explained firstly because their molar mass is rather close but also secondly because the HP $\beta C D$ s are in very large excess, meaning that in the solution there will be a great number of molecules that will not be able to interact with VA; however, all VA interacts with HP $\beta C D$ s. As such, the average molar mass will be much less impacted in the case of HP $\beta C D$ s, because of their large excess. The inclusion of VA and CZ in respectively $\beta C D$ and $\gamma C D$ has already been studied by previous authors [20-22], who proved the reality of the complexation, using complementary methods. The NMR data provided in this study confirms their findings. Indeed, NMR is one of the most used and useful method to obtain reliable information on molecular interactions, as it allows the determination of specific signals of the host molecule, the included molecule and the complex. In addition, the combined use of $1 \mathrm{H}$ shifts analysis and DOSY experiments brings double confirmation of the inclusion [46]. It was not possible using only the data available from the DOSY analysis to suggest possible molecular structures of inclusion complexes. Because of the size of the complexes, this analysis would need to be performed using 2D ROESY [43]. Therefore, and also because this information did not pertain to the objective of the study (it would not help in resolving the interaction), this analysis was not performed.

After having characterized the inclusion of the antibiotics in HPCDs, we evaluated the impact of the concentration of HP $\beta C D$ on the solubility profile of a $50 \mathrm{mg} \mathrm{mL}^{-1} \mathrm{VA}$ solution at $\mathrm{pH} 8$, in order to define the molar ratio (MR) of HPCD necessary to solubilize a high concentration of VA. We performed this phase solubility study to characterize the inclusion only for VA because it was the antibiotic that presented a visual precipitation when the $\mathrm{pH}$ was between 7.5 and 8.4. We choose to perform the phase solubility study with the data presented as in Figure 5 rather than as a Job's plot as the precipitation of VA in presence of CDs seemed to be influenced by time and could occur after $15 \mathrm{~min}$ to $24 \mathrm{~h}$. For $\mathrm{CZ}$, as this molecule is already soluble for $\mathrm{pH}$ ranging between 3 and 9 , a phase solubility study could not be performed. The results showed that the interaction phenomenon between VA and HP $\beta C D$ is a dynamic phenomenon that does not lead to covalent bonding and that the phenomenon is reversible at a given $\mathrm{pH}$. Indeed, the fact that the precipitation takes places (for lower MR) continuously after preparation, as shown in Figure 4 by the decrease of VA concentrations in solution over time, reflects an equilibrium inclined towards the dissociation of the HP $\beta C D / V A$ complex. This may be due to the release of a VA molecule, which, by precipitating, will alter the balance and cause the release of other molecules. By saturating the medium with $\operatorname{HP} \beta C D$, a shift of this balance in the direction of the formation of the complex seems to stabilise the inclusion. In our experimental conditions the molecular ratio (MR) required to solubilize all of the VA and therefore create a mixture without the formation of a precipitate during the time of the study was the ratio 10:1 (HP $\beta C D: V A)$.

In order to study the average impact of various factors, including cyclodextrin concentrations, on the solubilisation of ATB mixtures, a reduced experimental design was set up. Initially, the results obtained via the preliminary and characterisation studies directed research towards a 10:1 MR (HP $\beta C D: V A)$ in order to subsequently introduce a MR of $\mathrm{HP} \gamma \mathrm{CD}: \mathrm{CZ}$. Three main response factors were selected. Turbidity, which was the main discriminatory test, reflects the presence or absence of particles in suspension and therefore provides quantifiable information on the presence of precipitate. Thus, the target turbidity was for it to be as close to zero as possible. The size and number of subvisible particles was also measured and to be acceptable also has to be as small as possible since it will represent the number of particles in suspension in the solutions and therefore the number of insolubilized molecules. Lastly, osmolality was also measured, as this parameter should be, if possible, as close as possible to the value that can be found in contact with the eye, i.e., around 293 (iso-osmolar), knowing that a fairly wide tolerance exists. The use of 
an experimental design made it possible to greatly limit the number of experiments to be carried out while estimating the average impacts of our various parameters on the measured responses: only 84 experiments were carried out of 3888 possible combinations, which represents an economy of time and reduced reagents consumption. The results allowed the selection of two formulas to choose from. To choose between these formulations, several aspects were taken into account. First, the concentration corresponding to the HP $\beta C D$ : VA at 5:1 MR (125 $\mathrm{mg} \mathrm{mL}^{-1}$ of $\left.\mathrm{HP} \beta C D\right)$ was the maximum limit of concentration proposed by the European Medicines Agency, under which there was no described ocular toxicity and is therefore considered safe $[47,48]$. Thus, concentrations greater than $125 \mathrm{mg} \mathrm{mL}^{-1}$ of HP $\beta C D$ were above this limit. The use of higher concentrations would require a toxicity study which would have been long but above all irrelevant immediately since an alternative was possible with the addition of $\mathrm{HP} \gamma \mathrm{CD}$ at the MR of 3:1 (HP $\gamma \mathrm{CD}$ : CZ). Additionally, the 10:1 MRs had higher osmolalities in comparison with the experiments containing both an HP $\beta C D: V A$ 5:1 MR and an HP $\gamma C D$ : CZ 3:1 MR. This could have been a problem for future clinical applications, but as the eye does possess a high tolerance to the administration of solutions with a wide range of osmolalities [49,50], the United States Pharmacopoeia even giving a precise range of 171 to $1711 \mathrm{mOsm} . \mathrm{kg}^{-1}$ for adequate ocular tolerance [51], this should not be an issue. Finally, the solutions containing only $\mathrm{HP} \beta C \mathrm{CD}$ at a MR HP $\beta C D$ : VA of 10: 1 at $\mathrm{pH} 8$ were not stable for $24 \mathrm{~h}$ at $5^{\circ} \mathrm{C}$ since a precipitation appeared after one or two hours, unlike the optimal formulation containing the two cyclodextrins, whose mixture remained physically stable for at least $48 \mathrm{~h}$.

In order to decide between $\mathrm{pH} 7.5$ and 8 for the final formulation, several elements were taken into account. A pH of 7.5 would be of greater interest because the medium is less alkaline, and therefore, closer to the optimum chemical stability $\mathrm{pH}$ of VA and especially of $\mathrm{CZ}[52,53]$. However, the formulation at $\mathrm{pH} 8$ was found to be physically stable at $5{ }^{\circ} \mathrm{C}$ for at least $48 \mathrm{~h}$, and this was not the case for the same formulation at $\mathrm{pH} 7.5$, which is closer to the incompatibility $\mathrm{pH}$ limit when using HPCD. This solubility limit at $5{ }^{\circ} \mathrm{C}$ could subsequently cause storage problems since VA and especially $\mathrm{CZ}$ are known for being chemically instable at ambient temperatures [54-56]. In addition, pH 7.5 is the lowest $\mathrm{pH}$ that could be obtained using this formulation method for which the solubilization of CZ and VA was possible. This could be explained by the affinity of species with each other. Indeed, the net charge of $\mathrm{VA}$ is +1 below $\mathrm{pH} 7.3$ and the net charge of $\mathrm{CZ}$ is -1 below the same $\mathrm{pH}$. If the affinity of this form of VA is higher for CZ than for HPCD, it would preferentially associate with $\mathrm{CZ}$ and precipitate instead of being complexed by the HP $\beta C D$. In addition, it has been shown that an interaction is possible between the contents and the container for some LDPE packaging articles sterilized with gamma rays, leading to acidification of the eye drops [57]; in our case, this acidification could lead us below our $\mathrm{pH}$ limit and therefore lead to precipitation if the buffering capacity is exceeded.

After defining the optimal conditions, a scale-up was carried out, and the results of $\mathrm{pH}$, osmolality, turbidity measurements as well as subvisible particle counting confirmed the predictions of the DOE. It is, thus, possible to observe that these conditions give the best possible combination of results in comparison with the 84 other experiments. In addition, the solution resulting from the scale-up did not show any precipitation over a period of $48 \mathrm{~h}$ of refrigerated storage.

To verify that the formulation adopted did not show any loss of activity, bacteriological tests on the strains most found in the context of KB (Staphylococcus aureus and Pseudomonas aeruginosa $[1,2,5,6])$ were carried out. The antibacterial activity was also tested against Escherichia coli which has also been reported in bacterial keratitis and other ocular infections [58,59]. The three strains are also recommended as quality control by the French Society of Microbiology (SFM) and the EUCAST (European Committee of Antibiotic Susceptibility Testing) [60,61]. First, it is important to note that the concentrations are slightly below the expected concentrations of $25 \mathrm{mg} / \mathrm{mL}$ (between $21.64 \mathrm{mg} / \mathrm{mL}$ and $24.16 \mathrm{mg} / \mathrm{mL}$ ) which is surely linked to the uncertainty of the measurement of volumes in the syringe as well as volume expansion. In addition, before and after $0.22 \mu \mathrm{m}$ filtration 
the ATB concentration does not significantly decrease, which could have been the case if the HPCD/ATB complexes had been retained by the sterilizing filter. Bacteriological tests showed unchanged activity whether it was the antibiotic alone, the antibiotic in his HPCD or even the antibiotic in the final mixture. In addition, a synergistic effect of the two antibiotics as a mixture was possibly observed against the strains of $S$. aureus with larger diameters on average than those of the ATBs separately. This is faithful to what can be found in the literature [5,6] since the dual CZ/VA therapy makes it possible to target both the strains responsible for KB: Staphylococcus aureus (effect of CZ and VA) and Pseudomonas aeruginosa (effect of $\mathrm{CZ}$ ).

In this study, we managed to develop an ophthalmic formulation combining two normally incompatible antibiotics in order to treat BK. The association of two antibiotics in one formula could reduce by half the number of administrations, thus facilitating its administration by nurses and improving compliance to the treatment by patients. We used phosphate buffer at a final concentration of $50 \mathrm{mM}$, in order to maintain $\mathrm{pH}$ and to limit its variation. This buffer was chosen to avoid potential incompatibilities using carbonate buffer with ceftazidime [13], and is commonly used in many preparations as well as commercialized eye-drops at a concentration varying from 1.3 to $111.2 \mathrm{mM}[50,62]$. $\mathrm{HP} \beta C \mathrm{CD}$ were used at their maximum allowed concentration, as described by the European Medicines Agency which is of $12.5 \%$ [47]. If higher concentrations of antibiotics (such as $50 \mathrm{mg} \mathrm{mL}^{-1}$ ) were needed, it is very likely that higher concentrations of CDs would be needed, which is not necessarily possible either from an ocular tolerance point of view, but also from a strictly chemical view as the limits of solubilities of the CDs could be reached. In addition, the use of $\mathrm{HP} \gamma \mathrm{CD}$ could be further investigated in terms of safety for ocular use even if the EMA does not prohibit its use in ocular formulation and it has been reported to be used or tested in many extemporaneous preparations [63] such as for example but not exhaustively Nepafenac [64], Dexamethasone [65] and amphotericin B eye drops [66]. It is also to note that the cost of the eye drops could unfortunately be higher than the typical eye drops, but this should be compared to the direct and indirect cost of the classical formulation. Irritancy tests have not yet been performed as they were not part of the objectives of this study, which aimed to investigate the potential use of cyclodextrins for blocking the problematic incompatibility between VA and CZ. As the formulation achieved this first goal, the next step would be to evaluate its stability using physical, chemical and biological analytical methods over time after storage at various temperatures before evaluating its potential effect on eye tissues. Concerning permeation tests, as the antibiotics are not destined to be absorbed by the eye tissues but to have an effect on the bacteria forming the surface infection, these tests are not yet of high priority, but could be performed in a pre-clinical phase.

\section{Materials and Methods}

\subsection{Reactive and Reagents}

Preparation of the test solutions: vancomycin chlorhydrate and ceftazidime pentahydrate powders were obtained from Vancomycin Mylan ${ }^{\circledR}$ and Ceftazidime Mylan ${ }^{\circledR}$ powder for injectable solution vials (Mylan, Cournon-d'Auvergne, France). Deionized water (Versylene ${ }^{\circledR}$ ) was purchased from Fresenius Kabi (Louviers, France). HP- $\beta$-CD (CAS 128446-35-5) and HP- $\gamma$-CD (CAS 128446-34-4) were obtained from Sigma-Aldrich (St. Louis, $\mathrm{MO}, \mathrm{USA})$. Sodium dihydrogenophosphate dihydrate $\left(\mathrm{NaH}_{2} \mathrm{PO}_{4}\right)$ (Batch 190298040, exp. 30 November 2021), and disodic monohydrogenophosphate dodecahydrate $\left(\mathrm{Na}_{2} \mathrm{HPO}_{4}\right)$ (Batch 18129611, exp. 30 April 2023) were provided by Inresa (Bartenheim, France). Phosphoric acid at $850 \mathrm{mg} \mathrm{mL}^{-1}\left(\mathrm{H}_{3} \mathrm{PO}_{4}\right)$, and sodium hydroxide at $320 \mathrm{mg} \mathrm{mL}^{-1}(\mathrm{NaOH})$ (CAS: 1310-73-2), were purchased from Honeywell (Germany). Finally, deuterated water $\left(\mathrm{D}_{2} \mathrm{O}\right)$ and Tetra Deuteriated TrimethylSilylPropionate $\left(\mathrm{TSPd}_{4}\right)$ were purchased from Eurisotop (St. Aubin, France). 


\subsection{Study Design}

Firstly, a preliminary investigation of the CZ-VA incompatibility was realized. The potential impact of cyclodextrins in resolving incompatibilities between $\mathrm{CZ}$ and VA antibiotics was then studied by characterizing the inclusion of each antibiotic with its proposed corresponding HPCD by liquid NMR and complementary VA solubility test. After that, a design of experiments (DOE) was then performed to determine the impact of multiple parameters in order to inhibit the incompatibility and to define the best experimental condition to obtain a physically stable solution of the antibiotic mixture. Finally, the best solution given by the DOE was tested in a bacterial culture to verify the efficiency of the mixture compared to the individual solutions of antibiotics.

\subsubsection{Preparation of Solutions}

Antibiotics Solutions

For all experiments, VA and $\mathrm{CZ}$ powders were reconstituted in deionized water in order to obtain a $200 \mathrm{mg} \mathrm{m}^{-1}$ solution. Those solutions were then diluted to $25 \mathrm{mg} \mathrm{mL}^{-1}$ (for the preliminary study) or $50 \mathrm{mg} \mathrm{mL}^{-1}$ (for the NMR analyses, VA precipitation study, DOE experiments and microbial activity measurement). These final dilutions were performed either in water, in $50 \mathrm{mM}$ phosphate buffer aqueous solution or in HP-CD and phosphate buffer solution. The VA and CZ solution of $50 \mathrm{mg} \mathrm{mL}^{-1}$ were mixed in the final step at equal volumes to obtain a VA/CZ mixture at $25 \mathrm{mg} \mathrm{mL}^{-1}$ each. All adjustment to the desired $\mathrm{pH}$ was realized using a few microliters of $\mathrm{NaOH}$ or $\mathrm{H}_{3} \mathrm{PO}_{4}$ solutions with a SevenMulti ${ }^{\mathrm{TM}} \mathrm{pH}$-meter with an InLabTM Micro Pro glass electrode (Mettler-Toledo, Viroflay, France).

\section{Phosphate Buffer Solution}

Solutions of about $50 \mathrm{mM}$ phosphate buffer were prepared in order to maintain the $\mathrm{pH}$ of the antibiotic solutions at the desired values. Phosphate solutions at $\mathrm{pH} 3 ; 4 ; 6$ and 8 were prepared following the information given in Table 4 and completed to $50 \mathrm{~mL}$ with deionized water. Adjustment to the desired value was realized using few microlitres of $\mathrm{NaOH}$ or $\mathrm{H}_{3} \mathrm{PO}_{4}$ solution.

Table 4. Phosphate buffer solution composition in $50 \mathrm{~mL}$ at various $\mathrm{pH}$.

\begin{tabular}{ccccc}
\hline Phosphate Buffer Solution & pH 3 & pH 4 & pH 6 & pH 8 \\
\hline $\mathrm{H}_{3} \mathrm{PO}_{4}$ at $85 \mathrm{mg} \mathrm{mL}^{-1}(\mu \mathrm{L})$ & 2000 & 212 & - & - \\
$\mathrm{NaH}_{2} \mathrm{PO}_{4}, 2 \mathrm{H}_{2} \mathrm{O}(\mathrm{mg})$ & 205 & 230 & 202.5 & 1.1 \\
$\mathrm{Na}_{2} \mathrm{HPO}_{4}, 12 \mathrm{H}_{2} \mathrm{O}(\mathrm{mg})$ & - & - & 73.7 & 505 \\
\hline
\end{tabular}

Hydroxypropyl Cyclodextrins in Buffered Aqueous Solution

HP-CD solution $(\gamma$ and $\beta$ ) were prepared using the phosphate buffer solutions described previously. For each cyclodextrin, the appropriate quantity was weighed in order to obtain the proper molecular ratio for the corresponding antibiotic $(\mathrm{HP} \gamma \mathrm{CD}$ with $\mathrm{CZ}$ and VA with $\mathrm{HP} \beta C D$ ), and dissolved in HPCD phosphate buffer solution to obtain a final volume of $50 \mathrm{~mL}$. The concentration required to obtain a ratio of $1: 1$ with the antibiotic is respectively of $50.36 \mathrm{mg} \mathrm{mL}^{-1}$ and $144.5 \mathrm{mg} \mathrm{mL}^{-1}$ for respectively $\mathrm{HP} \beta \mathrm{CD}$ and $\mathrm{HP} \gamma \mathrm{CD}$.

\subsubsection{Preliminary Investigation of the Ceftazidime-Vancomycin Incompatibility}

To investigate the nature of the incompatibility, $\mathrm{pH}$ variations ranging from 3 to 9 and 4 to 9 were applied to respectively VA and CZ $25 \mathrm{mg} \mathrm{mL}^{-1}$ solutions, as well as to a CZ/VA mixture. A visual examination was realized for each solution during the $\mathrm{pH}$ variation in front of a white and black panel.

To further determine the nature of precipitant of the antibiotic mixture, a quantification of $\mathrm{CZ}$ and VA was performed in the solution supernatant of a CZ/VA mixture in phosphate buffer solution at $50 \mathrm{mM}$ adjusted to $\mathrm{pH} 7$ and 8 by high performance liquid 
chromatography (HPLC). In order to give additional proof about the composition of the precipitate, some of it was also recovered (separated from the supernatant by centrifugation) and dissolved with a $\mathrm{pH} 9$ buffer solution. The resulting solution was also analysed by HPLC.

The system used was a Prominence-I LC2030C 3D with diode array detection (Shimadzu France SAS, Marne La Vallée, France) and the associated software used to record and analyse the chromatograms was LabSolutions ${ }^{\circledR}$ version 5.82. After precipitation, each solution was centrifuged at $5000 \mathrm{rpm}$ for $10 \mathrm{~min}$, then diluted 1/10th in deionized water. The separation column used was a Nucleodur SB Gravity C18 $(250 \times 4.6 \mathrm{~mm}, 5 \mu \mathrm{m})$ column (Macherey Nagel, Hoerdt, France) and associated guard column $(12.5 \times 4.6 \mathrm{~mm})$. The mobile phase was an acetonitrile/ammonium acetate $100 \mathrm{mM}$ aqueous buffer adjusted with acetic acid to $\mathrm{pH} 5.8(10 / 90 \% v / v)$ in which the acetonitrile was HPLC quality (Chromasolv ${ }^{\circledR}$ for HPLC; Honeywell ${ }^{\circledR}$, Roissy CDG, France) and the water was sterile deionized (Versylene ${ }^{\circledR}$; Fresenius Kabi France, Louviers, France). The flow rate through the column for the analysis was set at $1.2 \mathrm{~mL} / \mathrm{min}$, with the column thermo-regulated to a temperature of $25^{\circ} \mathrm{C}$. The injection volume was $20 \mu \mathrm{L}$. The quantification wavelength was set up at $220 \mathrm{~nm}$ for vancomycin and $256 \mathrm{~nm}$ for ceftazidime. The method used allows vancomycin quantification with a mean accuracy of $99.04 \pm 4.5 \%$, repeatability's relative standard deviation (RSD) of $0.94 \%$ and intermediate precision's RSD of $1.07 \%$. As for ceftazidime quantification, the method's mean accuracy was of $99.04 \pm 2.8 \%$, repeatability's relative standard deviation (RSD) of $1.2 \%$ and intermediate precision is RSD of $2.61 \%$. It allows its quantification from 50 to $250 \mu \mathrm{g} \mathrm{mL}^{-1}$ with a determination coefficient $\mathrm{R}^{2}$ higher to 0.998 for both antibiotics. Method validation data are provided in the Supplementary Materials Files S1 and S2 (raw data).

\subsubsection{Antibiotics Inclusion Characterization in HP-CD NMR Analyses}

For each antibiotic, three kinds of solution and their 10 fold dilution in deuterated phosphate buffer solution were prepared: $1 \mathrm{~mL}$ of $200 \mathrm{mg} \mathrm{mL}^{-1}$ VA solution with $3 \mathrm{~mL}$ $\mathrm{pH} 3$ buffer solution; $1 \mathrm{~mL}$ water with $3 \mathrm{~mL} \mathrm{HP} \beta C D$ in $\mathrm{pH} 3$ buffer solution, $1 \mathrm{~mL}$ VA with $3 \mathrm{~mL} \mathrm{HP} \beta C D$ in $\mathrm{pH} 3$ buffer solution; $1 \mathrm{~mL} \mathrm{CZ}$ with $3 \mathrm{~mL} \mathrm{pH} 4$ buffer solution, $1 \mathrm{~mL}$ water with $3 \mathrm{~mL} \mathrm{HP} \gamma \mathrm{CD}$ in $\mathrm{pH} 3$ buffer solution; and $1 \mathrm{~mL} \mathrm{CZ}$ with $3 \mathrm{~mL} \mathrm{HP} \gamma \mathrm{CD}$ in $\mathrm{pH} 4$ buffer solution.

\section{${ }^{1} \mathrm{H}$ NMR-Spectroscopy Chemical Shifts Measurements}

The $1 \mathrm{H}$ NMR spectra were recorded at $298 \mathrm{~K}$ on a Bruker AVANCE III HD $500 \mathrm{MHz}$ spectrometer equipped with Bruker $5 \mathrm{~mm}$ inverse probe TXI $\left({ }^{1} \mathrm{H} /{ }^{13} \mathrm{C} /{ }^{15} \mathrm{~N}\right)$ with z-gradient coil probe. Solution of TSPd4 in D2O was used as internal reference for chemical shifts. To eliminate possible interactions between TSPd4 and the host molecule, the internal reference was introduced into a coaxial insert itself placed in the NMR tube. For all samples, a one dimensional ${ }^{1} \mathrm{H}$ NMR spectrum was acquired using a ZGPRESAT sequence with water pre-saturation at low power. A total of 8 or 16 scans were collected with a $90^{\circ} \mathrm{C}$ impulsion time of $10.2 \mu \mathrm{s}$, a $30 \mathrm{~s}$ relaxation time, an acquisition of $4.09 \mathrm{~s}$, a spectral window of $8000 \mathrm{~Hz}$ and $65 \mathrm{~K}$ data points zero-filled to $128 \mathrm{~K}$ before Fourier transformation with $0.3 \mathrm{~Hz}$ line broadening. In addition, the determination of the average molar mass of the two CDs was estimated by an assay with an internal reference (TSP-d4).

${ }^{1} \mathrm{H}$ NMR-Diffusion Measurements $\left({ }^{1} \mathrm{H}\right.$-DOSY)

The DOSY spectra were recorded at 298,0K (MeOD calibration and an air flow control of $5451 . \mathrm{h}^{-1}$ ) on a Bruker AVANCE III $500 \mathrm{MHz}$ spectrometer with a Prodigy TCI ${ }^{1} \mathrm{H} /{ }^{13} \mathrm{C} /{ }^{15} \mathrm{~N} / \mathrm{D}$ cryoprobe. DOSY experiments were performed using the bipolar longitudinal eddy current delay pulse sequence (ledbpgp2s) [42]. The durations of the magnetic field pulse gradients were optimized between 1 to $2 \mathrm{~ms}$ (to obtain complete dephasing of the signal with the maximum gradient strength) with $5 \mathrm{~ms}$ eddy current delay and spoil 
gradients of $600 \mu$ s with $17: 13 \%$ ratio. The pulse gradient has been incremented from 5 to $95 \%$ (to $65 \%$ for $\mathrm{H}_{2} \mathrm{O}$ diffusion) of the maximum strength in a linear ramp. The diffusion times have been optimized between to $40 \mathrm{~ms}$ (for $\mathrm{H}_{2} \mathrm{O}$ diffusion) to $100 \mathrm{~ms}$ (for antibiotics and cyclodextrins diffusion). Each DOSY experiment is a series of 16 spectra with $16 \mathrm{~K}$ data points, 4 dummy scans, 8 to 32 scans and a relaxation delay of 5 s. After Fourier transformation, phasing and baseline correction, the diffusion dimension has processed with the Bruker Dynamics Center software (2.7.1 version, Bruker, Ettlingen, Germany). For each sample, the residual water signal diffusion coefficient was measured and set as reference of DOSY spectra and diffusivity calculations $[43,44]$.

Influence of $\mathrm{HP} \beta \mathrm{CD}$ on Inclusion of VA and Its Precipitation

As vancomycin precipitated between $\mathrm{pH} 7.3$ to 8.4 , the impact of HP $\beta C D$ in the solubilisation of vancomycin was studied at $\mathrm{pH} 8$. For this purpose, a bulk solution of $380 \mathrm{mM}$ HP- $\beta$-CD in a $50 \mathrm{mM}$ phosphate buffer solution adjusted to $\mathrm{pH} 8$ was prepared from which various volumes were then added to $1 \mathrm{~mL}$ of a $200 \mathrm{mg} / \mathrm{mL}$ of VA and then completed with $50 \mathrm{mM}$ phosphate buffer solution to obtain at the end $4 \mathrm{~mL}$ of a $50 \mathrm{mg} / \mathrm{mL}$ of VA, as presented in Table 5.

Table 5. Preparation of vancomycin (VA)/2-hydroxypropyl- $\beta$-cyclodextrin (HP $\beta C D)$ solution for the study of the impact of $\mathrm{HP} \beta \mathrm{CD}$ on precipitation.

\begin{tabular}{ccccccccc}
\hline $\begin{array}{c}\text { Volume of } 380 \mathrm{mM} \mathrm{HP} \beta \mathrm{CD} \\
\text { solution at } \mathrm{pH} 8(\mathrm{~mL})\end{array}$ & 0 & 0.819 & 1.364 & 1.910 & 2.182 & 2.455 & 2.728 & 3.000 \\
$\begin{array}{c}\text { Volume } 50 \mathrm{mM} \text { phosphate } \\
\text { buffer solution pH } 8(\mathrm{~mL})\end{array}$ & 3.000 & 2.181 & 1.636 & 1.090 & 0.818 & 0.545 & 0.272 & 0 \\
$\begin{array}{c}\text { Volume of VA 200 mg/mL } \\
\text { solution }(\mathrm{mL})\end{array}$ & 1 & 1 & 1 & 1 & 1 & 1 & 1 & 1 \\
$\begin{array}{c}\text { Corresponding ratio } \\
\text { HP } \beta \text { CD:VA }\end{array}$ & $0: 1$ & $3: 1$ & $5: 1$ & $7: 1$ & $8: 1$ & $9: 1$ & $10: 1$ & $11: 1$ \\
\hline
\end{tabular}

Once the final $\mathrm{pH}$ was adjusted to 8 , each solution was stirred for $30 \mathrm{~min}$ and then centrifuged at $5000 \mathrm{rpm}$ for $10 \mathrm{~min}$, before being diluted in deionized water in order to quantify VA in the supernatant phase using a UV spectrophotometer (V670, Jasco France SAS, Lisses, France). The quantification was performed after $15 \mathrm{~min}, 24$ and $48 \mathrm{~h}$ after preparation in which centrifugation was realized before each analyses.

The validated quantification method had a calibration curve of $y=0.00447968 x-$ 0.0541038 , where $x$ is the absorbance at $280 \mathrm{~nm}$ and $y$ is VA concentration, with a $R^{2}$ of 0.999 and standard error of 1.58, allowing the quantification of VA between 75 and $175 \mu \mathrm{gL}^{-1}$.

\subsubsection{Determination of the Best Preparation Method by Design of Experiment}

The impact of multiple parameters on VA/CZ precipitation was studied using a DOE method following a D-optimal design. Seven parameters were chosen to be evaluated in an experimental design: concentrations of $\mathrm{HP} \beta \mathrm{CD}$ and of $\mathrm{HP} \gamma \mathrm{CD}$, $\mathrm{pH}$ of the $\mathrm{HP} \beta \mathrm{CD} / \mathrm{VA}$ and $\mathrm{HP} \gamma \mathrm{CD} / \mathrm{CZ}$ mixture, stirring duration of $\mathrm{HP} \beta \mathrm{CD} / \mathrm{VA}$ and $\mathrm{HP} \gamma \mathrm{CD} / \mathrm{CZ}$ mixture and final $\mathrm{pH}$ of the antibiotic mixture. The relative impact of these seven parameters was tested on five responses: visual aspect of the preparation, turbidity 2 categories of subvisible particles (bigger and smaller than $10 \mu \mathrm{m}$ ) and osmolality. For visual aspect assessment, a semi-quantitative (subjective) score was given between 0 and 10 (with 0 -no particles, 10-precipitation). Turbidity was measured using a 2100Q Portable Turbidimeter (Hach Lange, Marne La Vallée, France). Subvisible particles counting was performed using a HIAC Royco 9703 (Hach Lange, Noisy le Grand, France) equipped with a HRLD 400 EC detector, and osmolality was measured on $20 \mu \mathrm{L}$ samples using a freezing point osmometer (Model 2020, Advanced instruments Inc., Radiometer, SAS, Neuilly Plaisance, France).

The details concerning each parameter are presented in Table 6. In total, 84 experiments were carried out (see Supplementary Materials S1). The calculations of each parameters impact were performed using Modde ${ }^{\circledR}$ software (Sartorius, Goettingen, Germany), 
which was also used to establish the best preparation conditions based on turbidity values, visual examination and osmolality of the preparation.

Table 6. Parameters studied for their impact on the precipitation of ceftazidime (CZ)/vancomycin (VA) mixture solution. HP $\beta C D$ : 2-hydroxypropyl- $\beta$-cyclodextrin; HP $\gamma$ CD: 2-hydroxypropyl- $\gamma$ cyclodextrin.

\begin{tabular}{ccc}
\hline Parameters & Type & Studied Levels \\
\hline HP $\beta C D$ ratio (compared to VA) & Multilevel & $0 ; 2 ; 5$ and 10 \\
HP $\gamma$ CD ratio (compared to CZ) & Multilevel & $0 ; 1$ and 3 \\
VA/HP $\beta C D$ pH mixture & Quantitative & 3 to 6 \\
CZ/HP $\gamma$ CD pH mixture & Quantitative & 4 to 8 \\
VA $/ \mathrm{HP} \beta C D$ mixture time (hours) & Multilevel & $0.5 ; 1$ and 2 \\
CZ/HP $\gamma$ CD mixture time (hours) & Multilevel & $0.5 ; 1$ and 2 \\
pH of the final solution & Multilevel & $7 ; 7.5 ; 8$ and 8.5 \\
\hline
\end{tabular}

\subsubsection{Validation of the Preparation Method}

The two best set of experimental conditions, established by the DOE, were tested in order to prepare $48 \mathrm{~mL}$ of the CZ/VA mixture solution. For this purpose, $24 \mathrm{~mL}$ of each antibiotic solution (VA and $\mathrm{CZ}$ ) were prepared and mixed together according to the conditions defined by the DOE. The sterilization of the final solution was realized by filtration through $0.22 \mu \mathrm{m}$ filter in aseptic conditions, and the filtrated solution was quantified and compared to concentration before filtration. The filtrated solution was also placed in room temperature and at $5{ }^{\circ} \mathrm{C}$ to check for the absence of any precipitation after $24 \mathrm{~h}$, assessed by visual examination and turbidity measurements.

\subsubsection{Verification of the Efficiency Mixture of the Optimized Formula}

The efficiency of the best formula determined by DOE and after validation of the preparation method was verified by disk diffusion method against E. coli ATCC 25922, P. aeruginosa ATCC27853 and S. aureus ATCC29213. For this purpose, a sterile solution of CZ-VA mixture was prepared and then compared to $50 \mathrm{mM}$ phosphate $\mathrm{pH} 8$ buffer solution used as negative control, and to VA and CZ separate solutions used as reference response. A total of $1 \mu \mathrm{L}$ of the tested solution was applied on a blank disk set on a Mueller-Hinton agar plate inoculated with a $0.5 \mathrm{McF}$ bacterial suspension. The growth-inhibitory zone was measured after $18 \mathrm{~h}$ of incubation at $35^{\circ} \mathrm{C}$. Each test was performed in triplicate.

\section{Conclusions}

The data provided in this study supports the hypothesis that the usually incompatible mixture of VA and $\mathrm{CZ}$ is linked to the formation of an equimolar precipitate between the two oppositely charged drugs. The results of the DOE study showed that HPCD can resolve this incompatibly when the $\mathrm{pH}$ is higher than 7.5, and that an ophthalmic formulation combining these two essential antibiotics with HPCD can be made. It is has been proven that the antibiotics included in the HPCD maintained the bacterial activities of both molecules, which is essential to treat BK. It would, however, be essential to demonstrate the safety of this new formulation and its stability in order to be able to consider its use for human medicine.

Supplementary Materials: The following are available online at https:/ / www.mdpi.com/article/10 $.3390 /$ ijms221910538/s1: Supplementary Data File S1 (containing the additional data described in the manuscript) and S2 (containing all raw data).

Author Contributions: Conceptualization, Y.B., M.W. and P.C.; methodology, Y.B. and P.C.; software, Y.B., P.C., M.T., A.-S.B.-M. and M.Y.; validation, Y.B., P.C., M.T., A.-S.B.-M., M.Y., R.F. and V.S.; formal analysis F.N.-B., M.T., A.-S.B.-M. and R.F.; investigation, P.C., Y.B., F.N.-B., M.T., A.-S.B.-M. and R.F.; data curation, Y.B, F.N.-B., M.T., A.-S.B.-M., R.F., M.W., M.Y., M.J., P.C. and V.S.; writing-original draft preparation, Y.B., F.N.-B., P.C.; writing—review and editing, M.T., A.-S.B.-M., M.W., M.J., R.F. 
and V.S.; supervision, Y.B., P.C. and V.S.; project administration, P.C. All authors have read and agreed to the published version of the manuscript.

Funding: This research received no external funding.

Institutional Review Board Statement: Not applicable.

Informed Consent Statement: Not applicable.

Data Availability Statement: All raw data is provided in the Supplementary Data File S2.

Acknowledgments: The authors would like to thank Aurelien Freiz and Valentine Vannaire for their help in validating a method for the quantification of ceftazidime and vancomycin using HPLC.

Conflicts of Interest: The authors declare no conflict of interest.

\section{References}

1. Ting, D.S.J.; Ho, C.S.; Deshmukh, R.; Said, D.G.; Dua, H.S. Infectious Keratitis: An Update on Epidemiology, Causative Microorganisms, Risk Factors, and Antimicrobial Resistance. Eye 2021, 35, 1084-1101. [CrossRef] [PubMed]

2. Ung, L.; Bispo, P.J.M.; Shanbhag, S.S.; Gilmore, M.S.; Chodosh, J. The Persistent Dilemma of Microbial Keratitis: Global Burden, Diagnosis, and Antimicrobial Resistance. Surv. Ophthalmol. 2019, 64, 255-271. [CrossRef] [PubMed]

3. Puig, M.; Weiss, M.; Salinas, R.; Johnson, D.A.; Kheirkhah, A. Etiology and Risk Factors for Infectious Keratitis in South Texas. J. Ophthalmic Vis. Res. 2020, 15, 128-137. [CrossRef]

4. Soleimani, M.; Tabatabaei, S.A.; Mohammadi, S.S.; Valipour, N.; Mirzaei, A. A Ten-Year Report of Microbial Keratitis in Pediatric Population under Five Years in a Tertiary Eye Center. J. Ophthalmic Inflamm. Infect. 2020, 10, 35. [CrossRef] [PubMed]

5. Watson, S.L.; Gatus, B.J.; Cabrera-Aguas, M.; Armstrong, B.H.; George, C.R.; Khoo, P.; Lahra, M.M. Bacterial Ocular Surveillance System (BOSS) Sydney, Australia 2017-2018. Commun. Dis. Intell. 2020, 44. [CrossRef]

6. Sagerfors, S.; Ejdervik-Lindblad, B.; Söderquist, B. Infectious Keratitis: Isolated Microbes and Their Antibiotic Susceptibility Pattern during 2004-2014 in Region Örebro County, Sweden. Acta Ophthalmol. 2020, 98, 255-260. [CrossRef]

7. Austin, A.; Lietman, T.; Rose-Nussbaumer, J. Update on the Management of Infectious Keratitis. Ophthalmology 2017, 124, 1678-1689. [CrossRef]

8. Austin, A.; Schallhorn, J.; Geske, M.; Mannis, M.; Lietman, T.; Rose-Nussbaumer, J. Empirical Treatment of Bacterial Keratitis: An International Survey of Corneal Specialists. BMJ Open Ophthalmol. 2017, 2, e000047. [CrossRef]

9. Lin, A.; Rhee, M.K.; Akpek, E.K.; Amescua, G.; Farid, M.; Garcia-Ferrer, F.J.; Varu, D.M.; Musch, D.C.; Dunn, S.P.; Mah, F.S. Bacterial Keratitis Preferred Practice Pattern ${ }^{\circledR}$. Ophthalmology 2019, 126, P1-P55. [CrossRef]

10. Patel, S.; Preuss, C.V.; Bernice, F. Vancomycin. In StatPearls; StatPearls Publishing: Treasure Island, FL, USA, 2021.

11. Bui, T.; Preuss, C.V. Cephalosporins. In StatPearls; StatPearls Publishing: Treasure Island, FL, USA, 2021.

12. American Society of Health-System Pharmacists. Handbook on Injectable Drugs, 20th ed.; ASHP: Bethesda, MD, USA, 2018; ISBN 978-1-58528-615-7.

13. Fiscella, R.G. Physical Incompatibility of Vancomycin and Ceftazidime for Intravitreal Injection. Arch. Ophthalmol. 1993, 111, 730. [CrossRef]

14. Pubchem. Available online: https://pubchem.ncbi.nlm.nih.gov (accessed on 7 March 2021).

15. Loftsson, T. Cyclodextrins in Parenteral Formulations. J. Pharm. Sci. 2021, 110, 654-664. [CrossRef]

16. Loftsson, T.; Stefánsson, E. Cyclodextrins and Topical Drug Delivery to the Anterior and Posterior Segments of the Eye. Int. J. Pharm. 2017, 531, 413-423. [CrossRef]

17. Muankaew, C.; Loftsson, T. Cyclodextrin-Based Formulations: A Non-Invasive Platform for Targeted Drug Delivery. Basic Clin. Pharmacol. Toxicol. 2018, 122, 46-55. [CrossRef]

18. Chaudhari, P.; Ghate, V.M.; Lewis, S.A. Supramolecular Cyclodextrin Complex: Diversity, Safety, and Applications in Ocular Therapeutics. Exp. Eye Res. 2019, 189, 107829. [CrossRef]

19. Mura, P. Advantages of the Combined Use of Cyclodextrins and Nanocarriers in Drug Delivery: A Review. Int. J. Pharm. 2020, 579, 119181. [CrossRef] [PubMed]

20. Sofian, Z.M.; Abdullah, J.M.; Rahim, A.A.; Shafee, S.S.; Mustafa, Z.; Razak, S.A. Cytotoxicity Evaluation of Vancomycin and Its Complex with Beta-Cyclodextrin on Human Glial Cell Line. Pak. J. Pharm. Sci. 2012, 25, 831-837. [PubMed]

21. Zarif, M.S.; Afidah, A.R.; Abdullah, J.M.; Shariza, A.R. Physicochemical Characterization of Vancomycin and Its Complexes with Beta-Cyclodextrin. Biomed. Res. 2012, 23, 513-520.

22. Misiuk, W. Investigation of Inclusion Complex of HP- $\gamma$-Cyclodextrin with Ceftazidime. J. Mol. Liq. 2016, 224, 387-392. [CrossRef]

23. Ludwig, A.; Reimann, H. Eye. In Practical Pharmaceutics: An International Guideline for the Preparation, Care and Use of Medicinal Products; Bouwman-Boer, Y., Fenton-May, V., Le Brun, P., Eds.; Springer International Publishing: Cham, Switzerland, 2015; pp. 163-188. ISBN 978-3-319-15814-3.

24. Trolle-Lassen, C. Investigations into the Sensitivity of the Human Eye to Hypo- and Hypertonic Solutions as Well as Solutions with Unphysiological Hydrogen Ion Concentrations. Pharm. Weekbl. 1958, 93, 148-155. 
25. Noh, G.M.; Nam, K.Y.; Lee, S.U.; Lee, S.J. Precipitation of Vancomycin and Ceftazidime on Intravitreal Injection in Endophthalmitis Patients. Korean J. Ophthalmol. 2019, 33, 296-297. [CrossRef]

26. Lifshitz, T.; Lapid-Gortzak, R.; Finkelman, Y.; Klemperer, I. Vancomycin and Ceftazidime Incompatibility upon Intravitreal Injection. Br. J. Ophthalmol. 2000, 84, 117-118. [CrossRef]

27. Park, I.; Lee, S.J. Factors Affecting Precipitation of Vancomycin and Ceftazidime on Intravitreal Injection. J. Ocul. Pharmacol. Ther. 2013, 29, 23-26. [CrossRef] [PubMed]

28. Servais, H.; Tulkens, P.M. Stability and Compatibility of Ceftazidime Administered by Continuous Infusion to Intensive Care Patients. Antimicrob. Agents Chemother. 2001, 45, 2643-2647. [CrossRef] [PubMed]

29. Wazny, L.D.; Blake, P.G. Incompatibility of Vancomycin and Ceftazidime for Intraperitoneal Use. Perit. Dial. Int. 2002, $22,93-94$. [CrossRef]

30. Kwok, A.K.H.; Hui, M.; Pang, C.P.; Chan, R.C.Y.; Cheung, S.W.; Yip, C.M.S.; Lam, D.S.C.; Cheng, A.F.B. An In Vitro Study of Ceftazidime and Vancomycin Concentrations in Various Fluid Media: Implications for Use in Treating Endophthalmitis. Investig. Ophthalmol. Vis. Sci. 2002, 43, 1182-1188. [PubMed]

31. Nguyen, M. Handbook on Injectable Drugs. Crit. Care Med. 2013, 41, e190. [CrossRef]

32. Raju, B.; Bali, T.; Thiagarajan, G.; Rao, V.; Das, T.; Sharma, S. Physicochemical Properties and Antibacterial Activity of the Precipitate of Vancomycin and Ceftazidime: Implications in the Management of Endophthalmitis. Retina 2008, 28, 320-325. [CrossRef]

33. Ng, H.P.; Koh, K.F.; Tham, L.S. Vancomycin Causes Dangerous Precipitation When Infused with Gelatin Fluid. Anaesthesia 2000, 55, 1039-1040. [CrossRef]

34. Chemicalize-Instant Cheminformatics Solutions. Available online: https://chemicalize.com/welcome (accessed on 25 July 2021).

35. Johnson, J.L.H.; Yalkowsky, S.H. Reformulation of a New Vancomycin Analog: An Example of the Importance of Buffer Species and Strength. AAPS PharmSciTech 2006, 7, E33-E37. [CrossRef]

36. Abarca, R.L.; Rodríguez, F.J.; Guarda, A.; Galotto, M.J.; Bruna, J.E. Characterization of Beta-Cyclodextrin Inclusion Complexes Containing an Essential Oil Component. Food Chem. 2016, 196, 968-975. [CrossRef]

37. Sambasevam, K.P.; Mohamad, S.; Sarih, N.M.; Ismail, N.A. Synthesis and Characterization of the Inclusion Complex of $\beta-$ Cyclodextrin and Azomethine. Int. J. Mol. Sci. 2013, 14, 3671-3682. [CrossRef]

38. Williams, R.O.; Mahaguna, V.; Sriwongjanya, M. Characterization of an Inclusion Complex of Cholesterol and HydroxypropylBeta-Cyclodextrin. Eur. J. Pharm. Biopharm. 1998, 46, 355-360. [CrossRef]

39. Goswami, S.; Sarkar, M. Fluorescence, FTIR and 1H NMR Studies of the Inclusion Complexes of the Painkiller Lornoxicam with $\beta-, \gamma$-Cyclodextrins and Their Hydroxy Propyl Derivatives in Aqueous Solutions at Different PHs and in the Solid State. New J. Chem. 2018, 42, 15146-15156. [CrossRef]

40. Kfoury, M.; Landy, D.; Fourmentin, S. Characterization of Cyclodextrin/Volatile Inclusion Complexes: A Review. Molecules 2018, 23, 1204. [CrossRef] [PubMed]

41. Ja'far, M.H.; Nik Mohamed Kamal, N.N.S.; Hui, B.Y.; Kamaruzzaman, M.F.; Zain, N.N.M.; Yahaya, N.; Raoov, M. Inclusion of Curcumin in $\beta$-Cyclodextrins as Potential Drug Delivery System: Preparation, Characterization and Its Preliminary Cytotoxicity Approaches. Sains Malays. 2018, 47, 977-989. [CrossRef]

42. Wu, D.H.; Chen, A.D.; Johnson, C.S. An Improved Diffusion-Ordered Spectroscopy Experiment Incorporating Bipolar-Gradient Pulses. J. Magn. Reson. Ser. A 1995, 115, 260-264. [CrossRef]

43. Simova, S.; Berger, S. Diffusion Measurements vs. Chemical Shift Titration for Determination of Association Constants on the Example of Camphor-Cyclodextrin Complexes. J. Incl. Phenom. Macrocycl. Chem. 2005, 53, 163-170. [CrossRef]

44. Crutchfield, C.A.; Harris, D.J. Molecular Mass Estimation by PFG NMR Spectroscopy. J. Magn. Reson. 2006, 185, 179-182. [CrossRef] [PubMed]

45. Venuti, V.; Crupi, V.; Fazio, B.; Majolino, D.; Acri, G.; Testagrossa, B.; Stancanelli, R.; De Gaetano, F.; Gagliardi, A.; Paolino, D.; et al. Physicochemical Characterization and Antioxidant Activity Evaluation of Idebenone/Hydroxypropyl- $\beta$-Cyclodextrin Inclusion Complex. Biomolecules 2019, 9, 531. [CrossRef] [PubMed]

46. Fielding, L. Determination of Association Constants (Ka) from Solution NMR Data. Tetrahedron 2000, 56, 6151-6170. [CrossRef]

47. European Medicines Agency Cyclodextrins. Available online: https:/ / www.ema.europa.eu/en/cyclodextrins (accessed on 25 July 2021).

48. Stella, V.J.; He, Q. Cyclodextrins. Toxicol. Pathol. 2008, 36, 30-42. [CrossRef]

49. Dutescu, R.M.; Panfil, C.; Schrage, N. Osmolarity of Prevalent Eye Drops, Side Effects, and Therapeutic Approaches. Cornea 2015, 34, 560-566. [CrossRef]

50. Özalp, O.; Atalay, E.; Alataş, İ.Ö.; Küskü Kiraz, Z.; Yıldırım, N. Assessment of Phosphate and Osmolarity Levels in Chronically Administered Eye Drops. Turk. J. Ophthalmol. 2019, 49, 123-129. [CrossRef]

51. United States Pharmacopeia USP <771> Ophthalmic Products-Quality Tests, USP 43-NF38. Available online: https://www. uspnf.com/notices/usp-nf-final-print-edition (accessed on 8 September 2021).

52. Mathew, M.; Gupta, V.D. Stability of Vancomycin Hydrochloride Solutions at Various PH Values as Determined by HighPerformance Liquid Chromatography. Drug Dev. Ind. Pharm. 1995, 21, 257-264. [CrossRef] 
53. Zhou, M.; Notari, R.E. Influence of PH, Temperature, and Buffers on the Kinetics of Ceftazidime Degradation in Aqueous Solutions. J. Pharm. Sci. 1995, 84, 534-538. [CrossRef]

54. Kodym, A.; Hapka-Zmich, D.; Gołab, M.; Gwizdala, M. Stability of Ceftazidime in 1\% and 5\% Buffered Eye Drops Determined with HPLC Method. Acta Pol. Pharm. 2011, 68, 99-107.

55. Gautier, E.; Saillard, J.; Deshayes, C.; Vrignaud, S.; Lagarce, F.; Briot, T. Stability of a $50 \mathrm{Mg} / \mathrm{ML}$ Ceftazidime Eye-Drops Formulation. Pharm. Technol. Hosp. Pharm. 2018, 3, 219-226. [CrossRef]

56. Barbault, S.; Aymard, G.; Feldman, D.; Pointereau-Bellanger, A.; Thuillier, A. Stability of Vancomycin Eye Drops. J. Pharm. Clin. 1999, 18, 183-189.

57. Bouattour, Y.; Chennell, P.; Wasiak, M.; Jouannet, M.; Sautou, V. Stability of an Ophthalmic Formulation of Polyhexamethylene Biguanide in Gamma-Sterilized and Ethylene Oxide Sterilized Low Density Polyethylene Multidose Eyedroppers. Peer 2018 , 6, e4549. [CrossRef]

58. Teweldemedhin, M.; Gebreyesus, H.; Atsbaha, A.H.; Asgedom, S.W.; Saravanan, M. Bacterial Profile of Ocular Infections: A Systematic Review. BMC Ophthalmol. 2017, 17, 212. [CrossRef]

59. Zhai, H.; Bispo, P.J.M.; Kobashi, H.; Jacobs, D.S.; Gilmore, M.S.; Ciolino, J.B. Resolution of Fluoroquinolone-Resistant Escherichia Coli Keratitis with a PROSE Device for Enhanced Targeted Antibiotic Delivery. Am. J. Ophthalmol. Case Rep. 2018, 12, 73-75. [CrossRef]

60. European Committee on Antimicrobial Susceptibility Testing (EUCAST) Procedure for Establishing Zone Diameter Breakpoints and Quality Control Criteria for New Antimicrobial Agents, SOP Version 9.2 2020. Available online: https:/ / www.eucast.org/. (accessed on 13 September 2021).

61. European Committee on Antimicrobial Susceptibility Testing (EUCAST) Routine and Extended Internal Quality Control for MIC Determination and Disk Diffusion as Recommended by EUCAST. Version 10.0, 2020. 2020. Available online: https: / / www.eucast.org/ (accessed on 12 September 2021).

62. Berton, B.; Chennell, P.; Yessaad, M.; Bouattour, Y.; Jouannet, M.; Wasiak, M.; Sautou, V. Stability of Ophthalmic Atropine Solutions for Child Myopia Control. Pharmaceutics 2020, 12, 781. [CrossRef]

63. Bíró, T.; Aigner, Z. Current Approaches to Use Cyclodextrins and Mucoadhesive Polymers in Ocular Drug Delivery-A MiniReview. Sci. Pharm. 2019, 87, 15. [CrossRef]

64. Lorenzo-Veiga, B.; Sigurdsson, H.H.; Loftsson, T. Nepafenac-Loaded Cyclodextrin/Polymer Nanoaggregates: A New Approach to Eye Drop Formulation. Materials 2019, 12, 229. [CrossRef]

65. Mazet, R.; Choisnard, L.; Levilly, D.; Wouessidjewe, D.; Gèze, A. Investigation of Combined Cyclodextrin and Hydrogel Formulation for Ocular Delivery of Dexamethasone Acetate by Means of Experimental Designs. Pharmaceutics 2018, 10, 249. [CrossRef]

66. Chennell, P.; Yessaad, M.; Abd El Kader, F.; Jouannet, M.; Wasiak, M.; Bouattour, Y.; Sautou, V. Do Ophthalmic Solutions of Amphotericin B Solubilised in 2-Hydroxypropyl- $\gamma$-Cyclodextrins Possess an Extended Physicochemical Stability? Pharmaceutics 2020, 12, 786. [CrossRef] 